OPEN ACCESS

Edited by:

Sabine Levi,

Institut National de la Santé et de la

Recherche Médicale (INSERM),

France

Reviewed by: Stephen Brickley,

Imperial College London, United Kingdom Andrea Barberis, Fondazione Istituto Italiano di Technologia, Italy

${ }^{*}$ Correspondence: Joseph W. Lynch j.lynch@uq.edu.au Nela Durisic

n.durisic@uq.edu.au

Received: 20 February 2017 Accepted: 22 May 2017

Published: 08 June 2017

Citation:

Dixon CL, Sah P, Keramidas A,

Lynch JW and Durisic N

(2017) $\gamma 1$-Containing GABA-A

Receptors Cluster at Synapses

Where they Mediate Slower Synaptic

Currents than $\gamma 2$-Containing

GABA-A Receptors.

Front. Mol. Neurosci. 10:178

doi: 10.3389/fnmol.2017.00178

\section{$\gamma$ 1-Containing GABA-A Receptors Cluster at Synapses Where they Mediate Slower Synaptic Currents than $\gamma$ 2-Containing GABA-A Receptors}

\author{
Christine L. Dixon ${ }^{1}$, Pankaj Sah ${ }^{1}$, Angelo Keramidas ${ }^{1}$, Joseph W. Lynch ${ }^{1,2 *}$ and \\ Nela Durisic ${ }^{1 *}$ \\ ${ }^{1}$ Queensland Brain Institute, The University of Queensland, Brisbane, QLD, Australia, ${ }^{2}$ School of Biomedical Sciences, \\ The University of Queensland, Brisbane, QLD, Australia
}

GABA-A receptors $\left(G A B A_{A} R s\right)$ are pentameric ligand-gated ion channels that are assembled mainly from $\alpha(\alpha 1-6), \beta(\beta 1-3)$ and $\gamma(\gamma 1-3)$ subunits. Although $\mathrm{GABA}_{\mathrm{A}} \mathrm{Rs}$ containing $\gamma 2 \mathrm{~L}$ subunits mediate most of the inhibitory neurotransmission in the brain, significant expression of $\gamma 1$ subunits is seen in the amygdala, pallidum and substantia nigra. However, the location and function of $\gamma 1$-containing $\mathrm{GABA}_{A} R s$ in these regions remains unclear. In "artificial" synapses, where the subunit composition of postsynaptic receptors is specifically controlled, $\gamma 1$ incorporation slows the synaptic current decay rate without affecting channel deactivation, suggesting that $\gamma 1$-containing receptors are not clustered and therefore activated by diffuse neurotransmitter. However, we show that $\gamma 1$-containing receptors are localized at neuronal synapses and form clusters in both synaptic and extrasynaptic regions. In addition, they exhibit rapid membrane diffusion and a higher frequency of exchange between synaptic and perisynaptic populations compared to $\gamma 2 \mathrm{~L}$-containing $\mathrm{GABA}_{A} \mathrm{Rs}$. A point mutation in the large intracellular domain and a pharmacological analysis reveal that when a single non-conserved $\gamma 2 \mathrm{~L}$ residue is mutated to its $\gamma 1$ counterpart (T349L), the synaptic current decay is slowed from $\gamma 2 \mathrm{~L}$ - to $\gamma 1$-like without changing the clustering or diffusion properties of the receptors. In addition, previous fast perfusion and single channel kinetic experiments revealed no difference in the intrinsic closing rates of $\gamma 2 \mathrm{~L}$ and $\gamma 1$-containing receptors when expressed in HEK293 cells. These observations together with Monte Carlo simulations of synaptic function confirm that decreased clustering does not control $\gamma 1$-containing $\mathrm{GABA}_{A} \mathrm{R}$ kinetics. Rather, they suggest that $\gamma 1$ - and $\gamma 2 \mathrm{~L}$-containing receptors exhibit differential synaptic current decay rates due to differential gating dynamics when localized at the synapse.

Keywords: $\gamma 1$-subunit clustering, inhibitory neurotransmission, synapse, spillover, IPSC, artificial synapse, spt-PALM, UPAINT 


\section{INTRODUCTION}

GABA type-A receptor $\left(\mathrm{GABA}_{\mathrm{A}} \mathrm{R}\right)$ chloride channels mediate most of the fast inhibitory synaptic transmission in the mammalian brain. They are members of the pentameric ligandgated ion channel family, and are assembled from 19 known subunits: $\alpha 1-6 ; \beta 1-3 ; \gamma 1-3, \delta, \varepsilon, \pi, \theta$ and $\rho 1-3$. The subunit composition determines the pharmacology, gating kinetics and subcellular localization of these receptors. More than half of all synaptic $\mathrm{GABA}_{\mathrm{A}} \mathrm{Rs}$ contain the $\gamma 2$ subunit, most often in the $\alpha 1 \beta 2 \gamma 2$ stoichiometry (McKernan and Whiting, 1996), as a result of which $\gamma 2$-containing $\mathrm{GABA}_{\mathrm{A}}$ Rs have been studied intensely. However, much less is known about the functional properties of $\mathrm{GABA}_{\mathrm{A}}$ Rs containing $\gamma 1$.

Although the $\gamma 1$ subunit is weakly expressed throughout most of the brain, it is enriched in the central and medial amygdala, suggesting a physiological role in fear processing (Pirker et al., 2000; Esmaeili et al., 2009). Indeed, GABAergic inhibitory postsynaptic currents (IPSCs) with distinct pharmacological properties have been observed in central amygdala neurons (Delaney and Sah, 2001; Esmaeili et al., 2009). Given these observations, defining the physiological and pharmacological properties of $\gamma 1$-containing synaptic $\mathrm{GABA}_{\mathrm{A}} \mathrm{Rs}$, and the mechanisms by which they are modulated, may provide insights into the function of the circuits in which these receptors are involved.

Using "artificial synapses" it has been shown that IPSCs mediated by $\alpha 2 \beta 2 \gamma 1 \mathrm{GABA}_{\mathrm{A}}$ Rs exhibit significantly slower rise and decay times than those mediated by $\alpha 2 \beta 2 \gamma 2 \mathrm{~L} \mathrm{GABA}_{\mathrm{A}} \mathrm{Rs}$ (Dixon et al., 2014). However, the inherent activation and deactivation rates for $\alpha 2 \beta 2 \gamma 1$ and $\alpha 2 \beta 2 \gamma 2 \mathrm{~L} \mathrm{GABA}_{\mathrm{A}} \mathrm{Rs}$, when measured in macropatches using rapid agonist application or by single channel kinetic analysis, were similar (Dixon et al., 2014). Analysis of $\alpha 2 \beta 2 \gamma$ GABA $_{A}$ Rs incorporating chimeras of $\gamma 1$ and $\gamma 2 \mathrm{~L}$ subunits revealed that the intracellular loop and transmembrane domain 4 (TM4) regions of the $\gamma 1$ subunit were responsible for the slow decay kinetics of $\alpha 1 \beta 2 \gamma 1$-mediated IPSCs. Because the same region of the $\gamma 2$ subunit had previously been shown to be responsible for the synaptic localization of $\gamma 2$-containing receptors (Nymann-Andersen et al., 2002; Alldred et al., 2005), we originally postulated that the slow decay rate of IPSCs mediated by $\alpha 2 \beta 2 \gamma 1 \mathrm{GABA}_{\mathrm{A}}$ Rs was due to reduced receptor clustering at synapses. Here, we use a combination of electrophysiology, super-resolution imaging and Monte Carlo simulations to investigate the mechanisms governing the IPSC decay kinetics, the synaptic localization and the mobility of $\gamma 1$ - and $\gamma 2 \mathrm{~L}$-containing $\mathrm{GABA}_{\mathrm{A}}$ Rs. We find that $\gamma 1$-containing receptors exhibit slower synaptic current decay due to their differential inherent gating properties when localized at the neuronal synapse, rather than due to factors related to receptor mobility or proximity to the synapse.

\section{MATERIALS AND METHODS}

\section{Cell Culture}

Our methods for generating artificial synapses have recently been published (Dixon et al., 2015). Briefly, E18 timed-pregnant rats were euthanized via $\mathrm{CO}_{2}$ inhalation in accordance with procedures approved by the University of Queensland Animal Ethics Committee. Cortical neurons were rapidly removed, plated onto poly-D-lysine-coated coverslips in a 4 -well plate at a density of 80,000 cells/well, and cultured for 3-4 weeks until spontaneous IPSCs could be detected. Calcium phosphate was used to transfect HEK293 cells with $\mathrm{GABA}_{\mathrm{A}} \mathrm{R}$ subunits (see below) together with empty pEGFP plasmid for cell identification, and neuroligin $2 \mathrm{~A}$ to facilitate formation of synapses by the neurons onto the HEK293 cells. The transfection ratio was $1: 1: 4$ for $\alpha 2: \beta 2: \gamma$ $\mathrm{GABA}_{\mathrm{A}} \mathrm{R}$ subunits. One day post-transfection, the HEK293 cells were washed, trypsinized and plated on top of the neuronal cultures. Electrophysiological recordings were made 1-3 days after plating the cells. For imaging experiments, neuronal cultures were plated in a PDL-coated glass-bottomed dish at a density of 80-100 thousand cells per $29 \mathrm{~mm}$ dish. The transfection was performed 6-12 days after plating, and neurons were typically imaged between DIV 25 and DIV 28.

\section{Electrophysiology}

Whole-cell recordings were obtained using a $\mathrm{CsCl}$ internal pipette solution (145 mM CsCl, $2 \mathrm{mM} \mathrm{CaCl}_{2}, 2 \mathrm{mM} \mathrm{MgCl}_{2}$, $10 \mathrm{mM}$ glucose, $10 \mathrm{mM}$ HEPES, pH 7.4 CsOH). HEK293 cells were voltage clamped at $-70 \mathrm{mV}$ and perfused with a standard Ringer's external solution ( $140 \mathrm{mM} \mathrm{NaCl}, 5 \mathrm{mM} \mathrm{KCl}, 2 \mathrm{mM}$ $\mathrm{CaCl}_{2}, 1 \mathrm{mM} \mathrm{MgCl}_{2}, 10 \mathrm{mM}$ HEPES, pH 7.4 NaOH) at the rate of $1 \mathrm{ml} / \mathrm{min}$. Signals were digitized at $10 \mathrm{kHz}$ and Bessel filtered at $4 \mathrm{kHz}$. Recording equipment was either a Axon Multiclamp 700B with Digidata 1440 and pClamp 10 recording software (Molecular Devices), or Axon Multiclamp 700A (Molecular Devices) with ITC-16 computer interface (Instrutech) and Axograph X recording software.

Except where otherwise stated, experiments were performed at room temperature $\left(\mathrm{RT} ; 22.0 \pm 1.5^{\circ} \mathrm{C}\right)$. Where increased temperature was required, an in-line bath heater (Warner TC$324 \mathrm{~B}$ ) was set using a bath thermistor to $32.0 \pm 1.5^{\circ} \mathrm{C}$.

Recordings with series resistance above $20 \mathrm{M} \Omega$ were discarded. Capacitance of the HEK293 cells was typically $20 \mathrm{pF}$, resulting in a typical corner frequency of $398 \mathrm{~Hz}$. Because this was satisfactory for our experiments, series resistance compensation was not applied. Where drugs were applied, the events from the wash phase were averaged with the pre-drug period to control for any run-down or run-up.

Sliding templates in Axograph $\mathrm{X}$ were used to identify miniature events. Ten to ninety percent rise times were recorded and mono-exponential simplex fits applied to the decay period of individual events, which were then averaged for each cell.

\section{Drug Application}

Frozen DMSO stocks of NO711 (Tocris) were diluted 1000-fold in extracellular solution on the day of recording. Drug was gravity fed through a $0.5 \mathrm{~mm}$ ID Teflon tube targeted at the cell being recorded, which was switched between control and drug solution using a two-way valve upstream of the bath (exchange time $\sim 10 \mathrm{~s}$ ). Background bath perfusion of control 
solution helped to minimize the drug effect on surrounding cells.

\section{Molecular Biology}

In all experiments, we employed plasmid DNAs encoding human $\alpha 2, \beta 2, \gamma 1$ and $\gamma 2 \mathrm{~L} \mathrm{GABA}_{\mathrm{A}} \mathrm{R}$ subunits, all in the pcDNA3.1 plasmid vector. The $\alpha 2, \beta 2$ and $\gamma 1$ or $\gamma 2 \mathrm{~L}$ plasmids were co-transfected with pEGFP and neuroligin $2 \mathrm{~A}$ (in pNICE) at a ratio of 1:1:4:1:1. In the high-resolution imaging experiments, the $\alpha 2$ and $\gamma 2 \mathrm{~L}$ subunits were tagged near $\mathrm{N}$ terminus with superecliptic pHluorin (SEpH; Jacob et al., 2005; Tretter et al., 2008), a gift from Tija Jacob and Stephen Moss (Addgene plasmids 49169 and 49170). We used the existing AgeI and NheI enzyme sites to replace SEpH with the super-resolution protein $\mathrm{mEos} 2$ on the $\gamma 2 \mathrm{~L}$ subunit, which was a gift from Frederic Meunier (Queensland Brain Institute).

Because both mEos2- and pHluorin-tagged $\gamma 2 \mathrm{~L}$ constructs expressed well on the cell surface, we used them as a starting point for the construction of tagged $\gamma 1$ subunits. We amplified the human $\gamma 1$ subunit using Q5 polymerase (New England Biolabs) starting from amino acid 5 (forward primer XhoI $\gamma 1$ : CAAACTCGAGCTGGTTCCGCGTGGATCCGATGAAGATG ATGAGGATTTAACGG, reverse primer $\gamma 1$ SmaI GTAGCGT CACGTAGTCCCGGGGAATTTAGTCAGACTTCTTTTGATT TTTGC) and substituted it for the equivalent point on the $\gamma 2 \mathrm{~L}$ subunit using existing SmaI and XhoI enzyme sites. The resulting constructs retained the linker and signal sequences of the original $\gamma 2 \mathrm{~L}$ pHluorin subunit, thereby minimizing problems with surface expression, but the majority of the protein was $\gamma 1$.

\section{Monte Carlo Simulations}

Table 1 provides a list of default parameters used in the Monte Carlo simulations. Synapse geometry was defined using Cellblender 1.0 (MMBioS). In line with similar models (Montes et al., 2015), we used a simplified morphology with dimensions drawn from electron microscopy studies of synapses. The presynaptic bouton was represented by a box of dimensions $1 \mu \mathrm{m}$ width, $1 \mu \mathrm{m}$ depth and $0.5 \mu \mathrm{m}$ height. Below this, the postsynaptic cell membrane was modeled as a 2-dimensional plane, $64 \mu \mathrm{m}$ by $64 \mu \mathrm{m}$. The plane was positioned $20 \mathrm{~nm}$ below the surface of the presynaptic bouton, consistent with

TABLE 1 | Monte Carlo simulation parameters.

\begin{tabular}{lcl}
\hline Parameter & Starting value & References \\
\hline $\begin{array}{l}\text { Number of } \\
\text { channels } \\
\text { Synaptic cleft width }\end{array}$ & 300 & Nusser et al. (1997) \\
& $20 \mathrm{~nm}$ & $\begin{array}{l}\text { Schikorski and Stevens } \\
(1997), \text { Zuber et al. } \\
(2005)\end{array}$ \\
$\begin{array}{l}\text { GABA molecules } \\
\text { per vesicle }\end{array}$ & 3000 & $\begin{array}{l}\text { Clements (1996) } \\
\text { GABA diffusion rate }\end{array}$ \\
$\begin{array}{l}\text { Receptor gating } \\
\text { kinetics }\end{array}$ & $0.3 \mu \mathrm{m}^{2} / \mathrm{ms}$ & Nielsen et al. (2004) \\
Width of PSD & $\alpha 1 \beta 2 \gamma 2$ & Dixon et al. (2014) \\
& $200 \mathrm{~nm}$ & Kasugai et al. (2010)
\end{tabular}

The intrinsic receptor parameters were taken from a kinetic model for $\alpha 1 \beta 2 \gamma 2 L$ GABA $A_{A}$ Rs presented in Dixon et al. (2014). estimates of the synaptic cleft size. A total of 300 postsynaptic receptors were inserted into the plane and distributed across an area of $200 \mathrm{~nm}$ by $200 \mathrm{~nm}$. These dimensions are based on the larger end of the range of GABAergic synapses in brain tissue (Nusser et al., 1997; Kasugai et al., 2010). At the initiation of the simulation, 3000 molecules of neurotransmitter were released from a point source $1 \mathrm{~nm}$ below the center of the presynaptic terminal. In subsequent simulations, we increased the postsynaptic area without changing the number of receptors, to represent reduced receptor clustering that may be occurring in $\gamma 1$-containing artificial synapses (Table 2). As detailed below, we also systematically varied other parameters. A data-derived Markov model from our previous work was initially used to define receptor-agonist interactions and receptor opening; $\alpha 1 \beta 2 \gamma 2$ receptor kinetics were used to test the hypothesis because more rapid waveforms reduced simulation times and because our previous experiments showed that the slow kinetics associated with $\gamma 1$ subunits are independent of which $\alpha$ subunit was expressed (Dixon et al., 2014). To ensure that our results were not model-dependent, we repeated the simulation of increased clustering with a very different Markov scheme, incorporating mono-liganded channel openings co-operative binding and desensitization (Petrini et al., 2011). The fastest realistic diffusion rate for an amino acid in an aqueous environment is $0.76 \mathrm{\mu m}^{2} / \mathrm{ms}$ (Longsworth, 1953). However, narrow tortuous spaces and extracellular matrix molecules impede diffusion considerably. As neurotransmitter mobility when diffusing through neuropil is thought to be at least 2.5 -fold slower than in free solution (Rusakov et al., 2011), we chose a baseline diffusion rate of $0.3 \mu \mathrm{m}^{2} / \mathrm{ms}$. Simulations were run in mCell3.3 (MMBioS), using 20-50 consecutive seed values, which were averaged. Mono- or bi-exponential decay fits were carried out using Graphpad Prism on the averaged events.

\section{Microscopy Experiments}

All experiments were performed on an Elyra PS1 STORM/SIM microscope (Carl Zeiss Microscopy $\mathrm{GmbH}$ ) equipped with a $100 \times$ objective ( $\alpha$ Plan-Apochromat $100 \times 1.46$ NA oilimmersion), a focus lock system and an EMCCD camera Andor iXon Ultra 897 (Andor Technologies). A LF488/561-A-000 beam splitter and a FF01-523/610-25 emission filter (Semrock) were used to record $\mathrm{SEpH}$ and mEos2 fluorescence. Antibodies against GFP labeled with Alexa 647 and anti-synaptotagmin antibodies labeled with Oyster 550 or Oyster 650 (Synaptic Systems) were detected using LF 405/488/561/635-A-000ZHE and FF01-446/510/581/703-25 (Semrock). In dual color experiments, red and green channels were aligned with fluorescent microspheres (Molecular Probes) and the channel alignment module in Zen 2012 SP2 (black) software (Carl Zeiss Microscopy $\mathrm{GmbH}$ ). We collected movies of labeled synaptotagmin sites in live neurons and only bright immobile fluorescent puncta were used to determine presynaptic terminals. Synaptic GABA $\mathrm{A}_{\mathrm{A}}$ were then identified from the overlap of synaptotagmin-rich presynaptic terminals with GFP-labeled $\gamma$ subunit clusters. Cells were imaged in total internal reflection (TIRF) or highly inclined illumination 
TABLE 2 | Summary of Monte Carlo simulation results.

\begin{tabular}{|c|c|c|c|c|c|}
\hline Experiment & Diffusion $\left(\mu \mathrm{m}^{2} / \mathrm{ms}\right)$ & Cleft (nm) & Cluster (nm) & Peak (\# open receptors) & Decay tau (ms) \\
\hline \multirow[t]{4}{*}{ Changing synaptic area } & 0.3 & 20 & 200 & 26.5 & 17.1 \\
\hline & - & - & 400 & 16.1 & 16.8 \\
\hline & - & - & 800 & 6.8 & 17.0 \\
\hline & - & - & 1600 & 1.9 & 15.8 \\
\hline \multirow[t]{3}{*}{ Changing diffusion constant } & 0.1 & 20 & 200 & 68.5 & 18.5 \\
\hline & 0.3 & - & - & 26.5 & 17.1 \\
\hline & 0.8 & - & - & 8.0 & 17.2 \\
\hline \multirow[t]{3}{*}{ Changing synaptic cleft } & 0.3 & 10 & 200 & 52.0 & 17.0 \\
\hline & - & 15 & - & 35.8 & 17.5 \\
\hline & - & 20 & - & 26.5 & 17.1 \\
\hline \multirow[t]{4}{*}{5 release events $1 \mathrm{~ms}$ apart } & 0.3 & 20 & 200 & 94 & 25 \\
\hline & - & - & 400 & 76.7 & 27 \\
\hline & - & - & 800 & 41.9 & 28 \\
\hline & - & - & 1600 & 12.1 & 28 \\
\hline \multirow[t]{4}{*}{ Changing synaptic area $(\alpha 1 \beta 1 \gamma 2)$} & 0.3 & 20 & 200 & 194.3 & 79.6 \\
\hline & - & - & 400 & 156.7 & 79.5 \\
\hline & - & - & 800 & 92.9 & 81.6 \\
\hline & - & $-s$ & 1600 & 27.9 & 82.3 \\
\hline
\end{tabular}

In addition to receptor spread and cleft size, GABA diffusion coefficient was systematically increased to reflect the change of neurotransmitter diffusion with temperature. All results were averaged from 20 to 50 simulations of GABA release onto $\alpha 1 \beta 2 \gamma 2 L$ GABA $A$ Rs, except where $\alpha 1 \beta 1 \gamma 2$ receptors are specified. Reported time constants are from mono-exponential fits, except for $\alpha 1 \beta 1 \gamma 2$ receptors where weighted time constants from bi-exponential fits are reported.

mode in an enclosed chamber at RT, $(32.0 \pm 1.5)^{\circ} \mathrm{C}$ or $(36.0 \pm 1.5)^{\circ} \mathrm{C}$.

\section{sptPALM}

For single particle tracking super-resolution photoactivation localization microscopy (sptPALM) measurements were performed as previously described (Manley et al., 2010). A $560 \mathrm{~nm}$ laser was adjusted to $9-14 \mathrm{~W} / \mathrm{cm}^{2}$. mEos2 molecules were continuously converted with a $405 \mathrm{~nm}$ laser, the power of which was gradually increased. This ensured that only single mEos 2 molecules were converted and imaged at $560 \mathrm{~nm}$ while keeping their number constant, and well separated during the acquisition. The density of fluorescent particles was kept below 0.2 molecules $/ \mu \mathrm{m}^{2}$. For each cell expressing $\alpha 2 \beta 2 \gamma 1 \mathrm{GABA}_{\mathrm{A}} \mathrm{Rs}$, image stacks containing 2000-4000 images were collected at $40 \mathrm{~Hz}$. Cells expressing $\alpha 2 \beta 2 \gamma 2$ were imaged at either 20 or $40 \mathrm{~Hz}$. Both sampling rates resulted in the same diffusion coefficient.

\section{uPAINT}

Universal point accumulation imaging in nanoscale topography (uPAINT) experiments were performed as previously described (Giannone et al., 2010). We initially conducted two sets of experiments. In one, we used fluorescent nanobodies against GFP and in another, we used Alexa647-conjugated anti-GFP antibodies. Fluorescently tagged antibodies against GFP can accommodate more fluorophores and therefore yield longer trajectories, which significantly increases the accuracy of diffusion coefficients calculated from individual trajectories (Ernst and Köhler, 2013). However, they can cause crosslinking at higher concentrations. We compared diffusion parameters from these two experiments to determine an optimal concentration of anti-GFP antibodies at which single $\mathrm{GABA}_{\mathrm{A}} \mathrm{Rs}$ were labeled and potential cross-linking of the receptors was negligible. Cells were imaged in oblique illumination mode with a $642 \mathrm{~nm}$ laser at $20-30 \mathrm{~W} / \mathrm{cm}^{2}$.

\section{Data Analysis: sptPALM and UPAINT}

Single molecule fluorescent spots were localized in each frame and their position was followed over time using the TrackMate tracking algorithm (Jaqaman et al., 2008). A custom written MatLab (Math Works) routine was used to visualize individual trajectories and their corresponding mean-squared displacement (MSD) plots and to generate an average MSD vs. lag time plot. To improve the relative statistical error of individual MSD curves, only trajectories with 20 points or more were included in the analysis. It has previously been shown that when the diffusion coefficient is calculated from a linear fit to the first four points of the MSD vs. time plot, the relative error of the fit increases as the number of points decreases. As a consequence, the size of the diffusion coefficient distribution increases and the range of measured diffusion coefficients can still differ by a factor of two. In such cases the best estimate for the diffusion coefficient corresponds to the mean value (Qian et al., 1991; Ernst and Köhler, 2013). We therefore calculated the diffusion coefficients from the mean MSD vs. time plot of all trajectories recorded per cell.

Diffusion coefficient (D) was calculated by fitting the first four points of the average MSD curve to the equation:

$$
M S D(t)=4 D t+b
$$

An average confinement size was calculated by fitting MSD vs. time plot to the equation:

$$
M S D(t)=\frac{L^{2}}{3}\left(1-\exp \left(-\frac{12 D t}{L^{2}}\right)\right)+4 D_{\mathrm{mac}} t
$$


where $L^{2}$ is confinement area in which diffusion is constricted and $D_{\text {mac }}$ is diffusion coefficient at long timescale. An average localization precision if fluorescence spots was 40-60 nm.

\section{Statistical Analyses}

Statistical significance was evaluated with a Dunnet's multiple comparisons test, two-way analysis of variance (ANOVA) or Student's $t$-test as indicated in the text. The tests were run within GraphPad Prism or SigmaPlot computer programs. All data are presented as mean \pm SEM from $n$ cells and a minimum of two independent experiments.

\section{RESULTS}

\section{Electrophysiological Analysis of IPSCs in Artificial Synapses}

Using artificial synapses, it has been shown that spontaneous IPSCs mediated by $\alpha 2 \beta 2 \gamma 1 \mathrm{GABA}_{\mathrm{A}}$ Rs exhibited slower decay rates than those mediated by $\alpha 2 \beta 2 \gamma 2 L_{\text {GABA }}$ Rs (Dixon et al., 2014). By analyzing chimeras constructed of $\gamma 2 \mathrm{~L}$ and $\gamma 1$ subunits, it has been concluded that the TM4 region and the intracellular loop of $\gamma 2 \mathrm{~L}$ were required for the faster IPSC kinetics (Dixon et al., 2014). In the current work, we focused on this region in an attempt to identify which residues are responsible for functional differences between $\mathrm{GABA}_{\mathrm{A}}$ Rs containing $\gamma 1$ and $\gamma 2 \mathrm{~L}$ subunits. An amino acid sequence alignment of the relevant regions is displayed in Figure $\mathbf{1 A}$ and a schematic of the $\gamma$ subunit is shown in Figure 1B, with key non-conserved regions of the TM4 and intracellular domains highlighted in red.

Three TM4 residues were found to differ between $\gamma 1$ and $\gamma 2 \mathrm{~L}$ subunits, so we investigated the possibility that these were responsible for the slow decay rate (and possible loss of synaptic clustering) of $\alpha 2 \beta 2 \gamma 1 \mathrm{GABA}_{\mathrm{A}}$ Rs. All three $\gamma 2 \mathrm{~L}$ residues were mutated to their $\gamma 1$ counterparts and the resulting triple mutant subunit, designated $\gamma 2 \mathrm{~L}(\gamma 1 \mathrm{TM} 4)$, were co-expressed with $\alpha 2$ and $\beta 2$ subunits in HEK293 cells that were plated onto cultured neurons to form synaptic contacts (see "Materials and Methods" Section). IPSCs mediated by $\alpha 2 \beta 2 \gamma 2 \mathrm{~L}(\gamma 1 \mathrm{TM} 4) \mathrm{GABA}_{\mathrm{A}} \mathrm{Rs}$ exhibited a mean decay time constant of $36.4 \pm 2.6 \mathrm{~ms}(n=7)$, similar to that of wild-type $\alpha 2 \beta 2 \gamma 2 \mathrm{~L} \mathrm{GABA}_{\mathrm{A}} \mathrm{Rs}(47.3 \pm 3.3 \mathrm{~ms}$, $n=19)$ but faster than that of wild-type $\alpha 2 \beta 2 \gamma 1$ receptors $(60.1 \pm 3.4 \mathrm{~ms}, n=18$; Figures 1C,E). Next, we tested several non-conserved regions in the intracellular loop that are known to have functional importance in $\gamma 2$ subunits. The first of these was the $\gamma 2 \mathrm{~L}$ splice variant, which incorporates eight amino acids that are absent from both the short splice variant $(\gamma 2 S)$ and $\gamma 1$ (Figure 1A). GABA $_{A}$ Rs incorporating the $\gamma 2 S$ variant are differentially expressed across different brain regions, and have been reported to exhibit reduced synaptic clustering relative to receptors containing the $\gamma 2 \mathrm{~L}$ isoform (Meier and Grantyn, 2004). We found that the decay time constant for $\gamma 2 S$-containing receptors (41 $\pm 3 \mathrm{~ms} ; n=8$ ) was indistinguishable from that of $\gamma 2 \mathrm{~L}$-containing receptors (Figures 1C,E). This is consistent with the observation that transgenic mice suffer no deficit when only $\gamma 2 S$ or $\gamma 2 \mathrm{~L}$ is expressed (Baer et al., 2000). The rise times of synaptic currents are sensitive to the GABA concentration profile and can reflect changes in clustering propensity. We therefore calculated IPSC $10 \%-90 \%$ rise times for the $\gamma$ subunit variants listed above and found that $\gamma 1$-containing receptors have slower rise times than $\gamma 2$-containing $\mathrm{GABA}_{\mathrm{A}}$ Rs (Supplementary Figure S1A).

$\mathrm{GABA}_{\mathrm{A}}$ Rs have a number of phosphorylation sites that modulate their trafficking and their ability to bind to other proteins (Nakamura et al., 2015). Protein kinase C phosphorylates $\gamma 2 \mathrm{~L}$ at Ser 327 (Moss et al., 1992), and de-phosphorylation of this site leads to decreased $G_{A B A} R$ clustering at synapses (Muir et al., 2010). We therefore investigated expression of receptors in which the phosphorylated residue in $\gamma 2 \mathrm{~L}$ had been mutated to the $\gamma 1$ equivalent. Mutation of serine $327\left(\alpha 2 \beta 2 \gamma 2 \mathrm{~L}^{\mathrm{S} 327 \mathrm{~T}}\right)$ resulted in IPSCs with a mean decay time constant of $45.6 \pm 3.9 \mathrm{~ms}(n=5)$, similar to wild-type $\alpha 2 \beta 2 \gamma 2 \mathrm{~L} \mathrm{GABA}_{\mathrm{A}} \mathrm{Rs}$ (Figures 1C,E). Mutation of a second putative phosphorylation site, Thr $349\left(\alpha 2 \beta 2 \gamma 2 \mathrm{~L}^{\mathrm{T} 349 \mathrm{~L}}\right)$, resulted in IPSCs with a mean decay time constant of $62 \pm 6.8 \mathrm{~ms}$ $(n=8)$, much closer to the decay time constant seen with the $\alpha 2 \beta 2 \gamma 1 \mathrm{GABA}_{\mathrm{A}} \mathrm{Rs}$, and significantly different from that of wild-type $\alpha 2 \beta 2 \gamma 2 \mathrm{~L} \mathrm{GABA}_{\mathrm{A}} \mathrm{Rs}(p=0.04$, Dunnett's multiple comparisons test). Converse mutation at the corresponding residue in the $\gamma 1$ subunit, $\alpha 2 \beta 2 \gamma 1^{\mathrm{L} 353 \mathrm{~T}}$, resulted in IPSCs with a faster decay time constant $(41.7 \pm 3.1 \mathrm{~ms}, n=8$; Figures 1D,E). A two-way ANOVA comparing the results of wild-type $\gamma 1$ and $\gamma 2 \mathrm{~L}$ containing $\mathrm{GABA}_{\mathrm{A}}$ Rs to those containing the $\gamma 1^{\mathrm{L} 353 \mathrm{~T}}$ and $\gamma 2 \mathrm{~L}^{\mathrm{T} 349 \mathrm{~L}}$ subunits showed that the residue at this position determined the IPSC decay time constant $(p=0.0004)$. The same analysis performed for rise time did not show a significant effect $(p=0.33)$. This demonstrates that two amino acids, $\gamma 2 \mathrm{~L}$ Thr349 and $\gamma 1$ Leu353, are critical in setting the decay kinetics of IPSCs containing these subunits.

We next sought to determine whether phosphorylation of $\gamma 2 \mathrm{~L}$ Thr349 also induces a slowing in IPSC decay rate. CaMKII is absent from HEK293 cells (Houston and Smart, 2006), although these cells do express other kinases that would act as a substitute (Zagranichnaya et al., 2005). We employed a mutagenesis approach to investigate this question, first substituting $\gamma 2 \mathrm{~L}$ Thr349 with negatively charged glutamate as a phosphomimetic. We found that IPSCs mediated by $\alpha 2 \beta 2 \gamma 2 \mathrm{~L}^{\mathrm{T} 349 \mathrm{E}} \mathrm{GABA}_{\mathrm{A}} \mathrm{Rs}$ had similar kinetics $(46.3 \pm 2.5 \mathrm{~ms}, n=6)$ to those mediated by wild-type $\alpha 2 \beta 2 \gamma 2 \mathrm{~L} \quad \mathrm{GABA}_{\mathrm{A}} \mathrm{Rs}$ (Figure 1E). This could indicate either that phosphorylation is not involved in this phenomenon, or that $\gamma 2 \mathrm{~L}$ Thr349 is a target for a kinase endogenous to HEK293 cells, and is phosphorylated at baseline. However, if this was true, then substituting with the non-polar, non-phosphorylable valine should make the events more similar to those observed in $\alpha 2 \beta 2 \gamma 1$ GABA $_{\mathrm{A}}$ Rs, which was not the case; events from synapses containing $\alpha 2 \beta 2 \gamma 2 \mathrm{~L}^{\mathrm{T} 349 \mathrm{~V}} \mathrm{GABA}_{\mathrm{A}} \mathrm{Rs}$ exhibited a decay time constant of $50.6 \pm 2.9 \mathrm{~ms}(n=8)$. We also investigated the conservative Ser and Asn mutations and found no significant change in decay time constants (Figure 1E). Taken together these results lead us to conclude that the difference in IPSC decay rate between $\alpha 2 \beta 2 \gamma 1$ and $\alpha 2 \beta 2 \gamma 2 L_{\text {GABA }}$ Rs is not driven by phosphorylation of the $\gamma 2$ subunit. 
A

Y1 320 HYFTSNQKGKTATKDRKLKNKASM---------TPGLHPGSTLIPMNNISVPQE--DDYGY

Y2L 318 HYFVSNRK---PSKDKDKKKKNPLLRMFSFRAPTIDIRPRSATIQMNNATHLQERDEEYGY

S327T ' $\mathrm{L}$ ' insert T349L

TM4

Y1 370 QCLEGKDCASFFCCFEDCRTGSWREGRIHIRIAKIDSYSRIFFPTAFALFNLVYWVGYLYL

Y2L 368 ECLDGKDCASFFCCFEDCRTGAWRHGRIHIRIAKMDSYARIFFPTAFCLFNLVYWVSYLYL

GABARAP binding site A406S C415A S424G

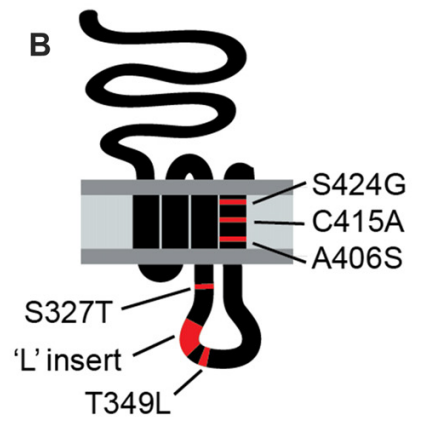

C

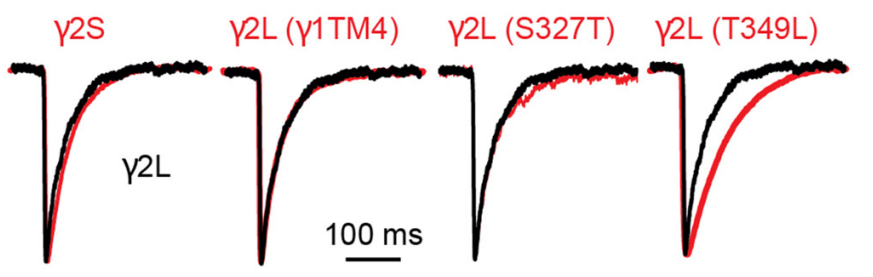

D Y1 (L353T)

E

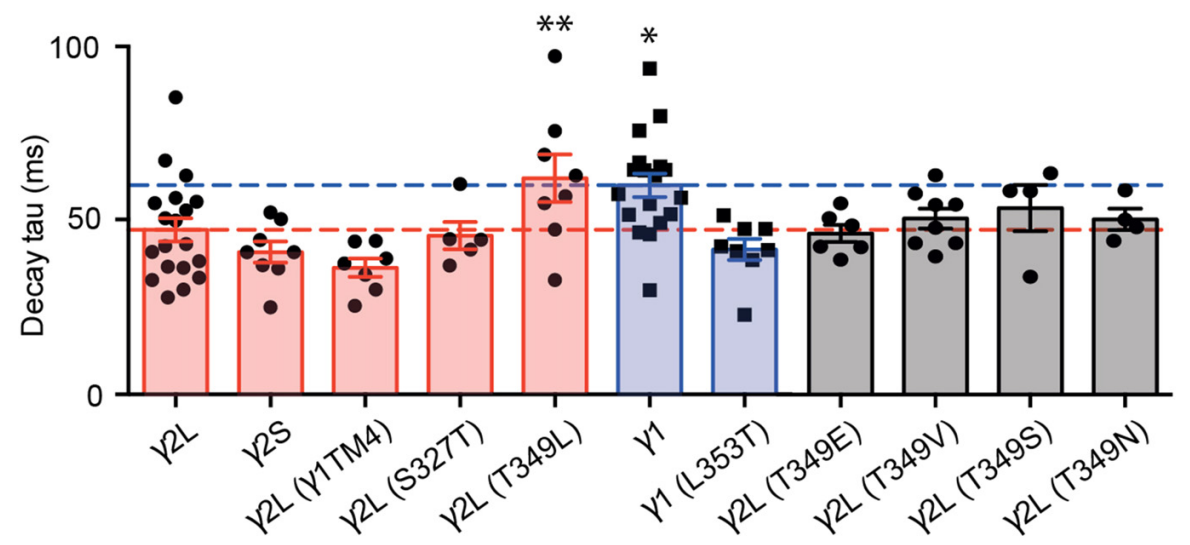

FIGURE 1 | The inhibitory postsynaptic current (IPSC) decay time constant was increased by the T349L mutation to the $\gamma 2$ subunit and decreased by the converse (L353T) mutation to the $\gamma 1$ subunit. (A) Amino acid sequence alignment of the large intracellular and transmembrane domain 4 (TM4) domains of the $\gamma 1$ and $\gamma 2$ subunits. Non-conserved residues or regions that were investigated in this study are highlighted in red. (B) Membrane topology of a $\gamma 2$ subunit indicating the location of residues and domains highlighted in red in (A). (C) Average waveforms from individual representative HEK293 cells that expressed $\alpha 1 \beta 2 \gamma 2 \mathrm{~L}$ GABA-A receptors $\left(G_{A B A} A_{A}\right.$ s; black) or $\alpha 1, \beta 2$ and the indicated $\gamma 2$ subunit variant (red). (D) Average waveform from a representative HEK293 cell that expressed $\alpha 1 \beta 2 \gamma 1 \mathrm{GABA}_{A}$ Rs (black) compared with a HEK293 cell expressing $\alpha 1 \beta 2 \gamma^{1{ }^{L 353 T} \mathrm{GABA}}{ }_{A} R s$ (blue). (E) Mean decay time constants recorded from artificial synapses incorporating the indicated $\gamma$ subunit variant. Individual data points represent the average of all IPSCs recorded in a single cell and error bars indicate the SEM. Bar plots are color coded according to whether they represent $\gamma 2 \mathrm{~L}$ to $\gamma 1$ subunit changes (red), $\gamma 1$ to $\gamma 2 \mathrm{~L}$ subunit changes (blue) or $\gamma 2 \mathrm{~L}$ T349 phosphorylation site mutations (gray). Some of the data from $\gamma 2 \mathrm{~L}$ - and $\gamma 1$-containing receptors have previously been published (Dixon et al., 2014). Horizontal lines indicate mean decay time constants for $\gamma 2 \mathrm{~L}$ (red) and $\gamma 1$ (blue). ${ }^{*} P<0.05,{ }^{*} P<0.01$ relative to $\gamma 2 \mathrm{~L}$ by one-way analysis of variance (ANOVA) followed by Dunnett's post hoc test for multiple comparisons.

We next sought to understand the mechanism underlying the difference in IPSC decay rates between $\alpha 2 \beta 2 \gamma 1$ and $\alpha 2 \beta 2 \gamma 2 \mathrm{~L}$ $\mathrm{GABA}_{\mathrm{A}}$ Rs. One possibility is that $\alpha 2 \beta 2 \gamma 1 \mathrm{GABA}_{\mathrm{A}}$ Rs are less clustered than $\alpha 2 \beta 2 \gamma 2 \mathrm{~L} \mathrm{GABA}_{\mathrm{A}} \mathrm{Rs}$ (Dixon et al., 2014), in which case the slower kinetics of $\alpha 2 \beta 2 \gamma 1$-mediated IPSCs could be caused by the delay in neurotransmitter reaching the declustered, peri-synaptic receptors. Synaptically released GABA is cleared by a combination of diffusion and uptake by the GABA transporter, GAT1. In situ, it is clear that the transporter is critical, reducing the spread of GABA and activation of peri-synaptic receptors (Gonzalez-Burgos et al., 2009). We therefore investigated whether blocking GAT1 differentially affected IPSCs mediated by $\alpha 2 \beta 2 \gamma 1$ and $\alpha 2 \beta 2 \gamma 2 \mathrm{~L}$ GABA $_{\mathrm{A}}$ Rs. However, blocking GAT1 activity with the specific blocker, NO711 $(10 \mu \mathrm{M})$, had no impact on the kinetics of IPSCs mediated by either receptor (Figure 2). Decay time constants for $\alpha 2 \beta 2 \gamma 2 \mathrm{~L}-$ mediated IPSCs were $109 \pm 6 \%$ of control $(n=5)$, and for $\alpha 2 \beta 2 \gamma 1$-mediated IPSCs were $104 \pm 3 \%$ of control $(n=6)$. 


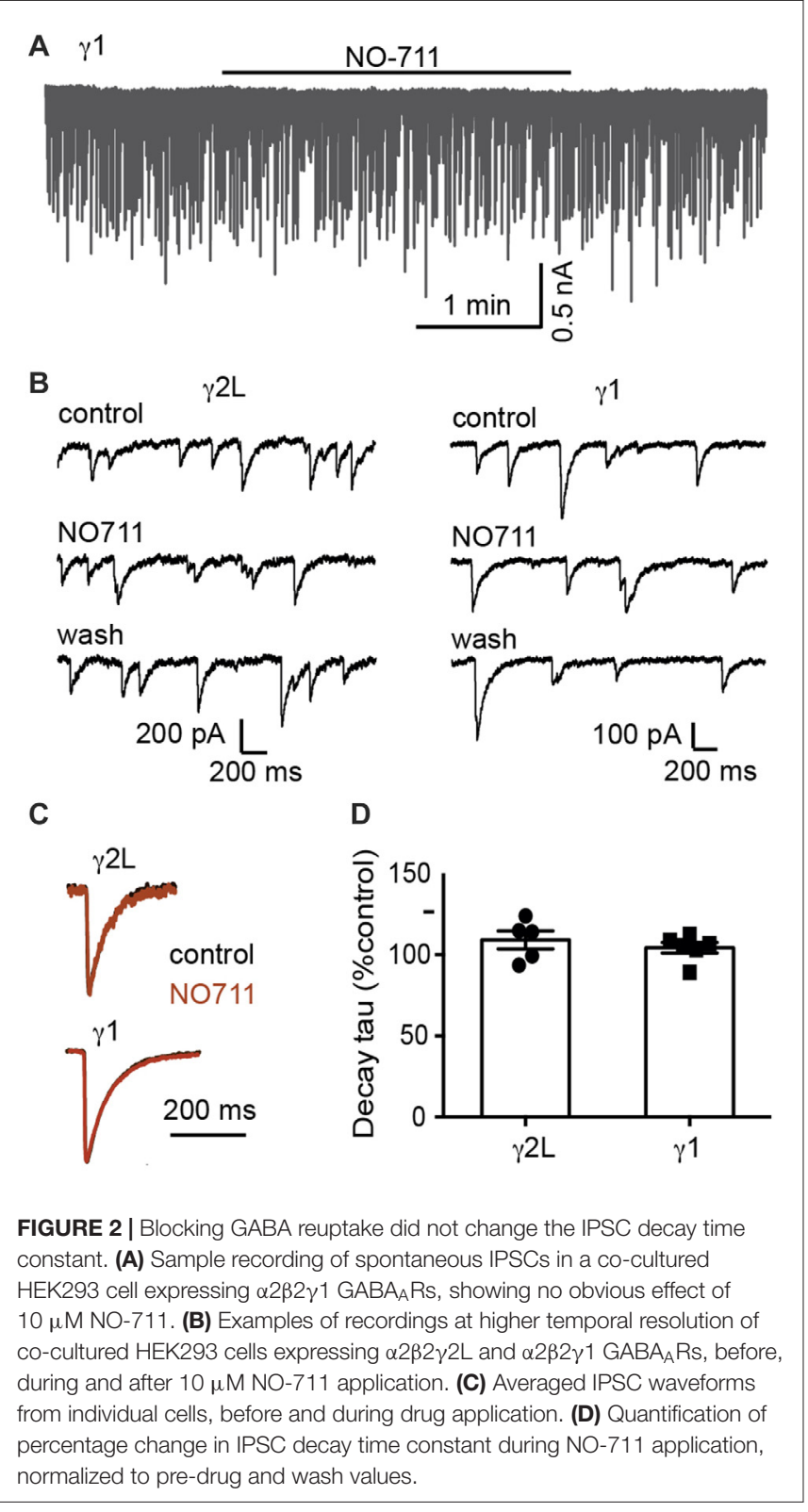

The intrinsic deactivation rates of $\alpha 2 \beta 2 \gamma 1$ are identical to those of $\alpha 2 \beta 2 \gamma 2 \mathrm{~L} \mathrm{GABA}_{\mathrm{A}}$ Rs when expressed in a non-synaptic context (Dixon et al., 2014). If the difference in IPSC decay rate is determined by differences in molecular interactions (i.e., gating conformational changes) within the protein, the kinetics of channel deactivation should be temperature sensitive, with a Q10 > 2 (Postlethwaite et al., 2007). In contrast, if differences in the neurotransmitter diffusion rate control the IPSC decay rate difference, the temperature sensitivity should exhibit a reduced Q10 of 1-2 (Wahl et al., 1996). We therefore tested the temperature sensitivity of IPSCs mediated by $\alpha 2 \beta 2 \gamma 1$ and $\alpha 2 \beta 2 \gamma 2 \mathrm{~L} \mathrm{GABA}_{\mathrm{A}}$ Rs at 22 and $32^{\circ} \mathrm{C}$ (Figure $3 \mathrm{~A}$ ). At $32^{\circ} \mathrm{C}, \alpha 2 \beta 2 \gamma 1$-mediated IPSCs exhibited an average decay time constant of $20.3 \pm 2.1 \mathrm{~ms}(n=7)$, whereas for $\alpha 2 \beta 2 \gamma 2 \mathrm{~L}$ mediated IPSCs this value was $15.7 \pm 1.5 \mathrm{~ms}(n=7)$. When these data were compared to the respective values obtained at $22^{\circ} \mathrm{C}$, a Q10 value of 3 was obtained for both receptor isoforms (Figures 3B,C). A two-way ANOVA showed that temperature was a key determinant of decay the time constant $(p<0.0001)$, as was receptor type, in line with previous results $(p=0.03)$. IPSC rise times follow similar trend (Supplementary Figure S1B). From this, we infer that the difference in IPSC decay rate between the two subtypes is dominated by differential molecular interactions (i.e., gating conformational changes) when in the synapse and not by diffusion of GABA.

\section{Monte Carlo Simulations}

To more closely examine effects of synaptic spillover on IPSC kinetics, we turned to Monte Carlo simulations of synapse function. A list of the initial default parameters used to generate a model of a functional synapse is given in Table $\mathbf{1}$ and the kinetic schema are shown in Supplementary Figure S2A. Initially, the synapse contained a fixed number of receptors (300) spread out over an increasing postsynaptic surface area. Snapshots taken at indicated time intervals during one such simulation are shown in Figure 4A. With a postsynaptic area of $200 \mathrm{~nm}$ by $200 \mathrm{~nm}$, a single vesicle of transmitter activated $69 \mathrm{GABA}_{\mathrm{A}} \mathrm{Rs}$, and the evoked IPSC exhibited a rise time of $1.6 \mathrm{~ms}$ and a decay time constant of $12.9 \mathrm{~ms}$, similar to the results obtained in artificial synapses (Dixon et al., 2014). With the same receptors spread out over a larger area $(400 \times 400 \mathrm{~nm})$, the number of activated $\mathrm{GABA}_{\mathrm{A}}$ Rs decreased to 51, and the evoked IPSC had a rise time of $1.7 \mathrm{~ms}$ and a decay time constant of $12.7 \mathrm{~ms}$. This trend towards a reduced number of open receptors with little change in synaptic kinetics continued with the increase of postsynaptic surface areas (Figures $\mathbf{4 B}, \mathbf{C}$ ). Systematic alterations in the GABA diffusion rate, which would be caused by temperature changes in vivo, or in the width of the synaptic cleft did not change this relationship (Table 2). Similarly, extending the synaptic release time course, by simulating the release of five vesicles at $1 \mathrm{~ms}$ intervals, had no effect on this relationship (Table 2). Finally, we again tested the impact of receptor spread but this time used a very different receptor model, in which monoliganded openings caused a decrease in decay rate when receptors are located more diffusely (Supplementary Figure S2B; Petrini et al., 2011). However, this model also failed to show that reduced clustering could be a plausible mechanism for slow decay times at $\alpha 2 \beta 2 \gamma 1$-containing synapses (Figure 4D).

\section{Single-Particle Tracking of GABA $A_{A}$ s in HEK293 Cells}

Ligand-gated ion channel receptors can move rapidly between extrasynaptic regions and the synaptic stabilization zone (Gerrow and Triller, 2010; Choquet and Triller, 2013; Salvatico et al., 2015). Changes in diffusion dynamics often occur within receptor clusters, and depend on receptor subtype, phosphorylation status and interactions with other proteins (Muir et al., 2010; Muir and Kittler, 2014; Lévi et al., 2015). To test if there is a link between $\mathrm{GABA}_{\mathrm{A}} \mathrm{R}$ membrane stability and IPSC kinetics, we employed single-particle tracking to follow individual receptors containing $\gamma 1^{\mathrm{mEos} 2}, \gamma 2 \mathrm{~L}^{\mathrm{mEos} 2}$ 

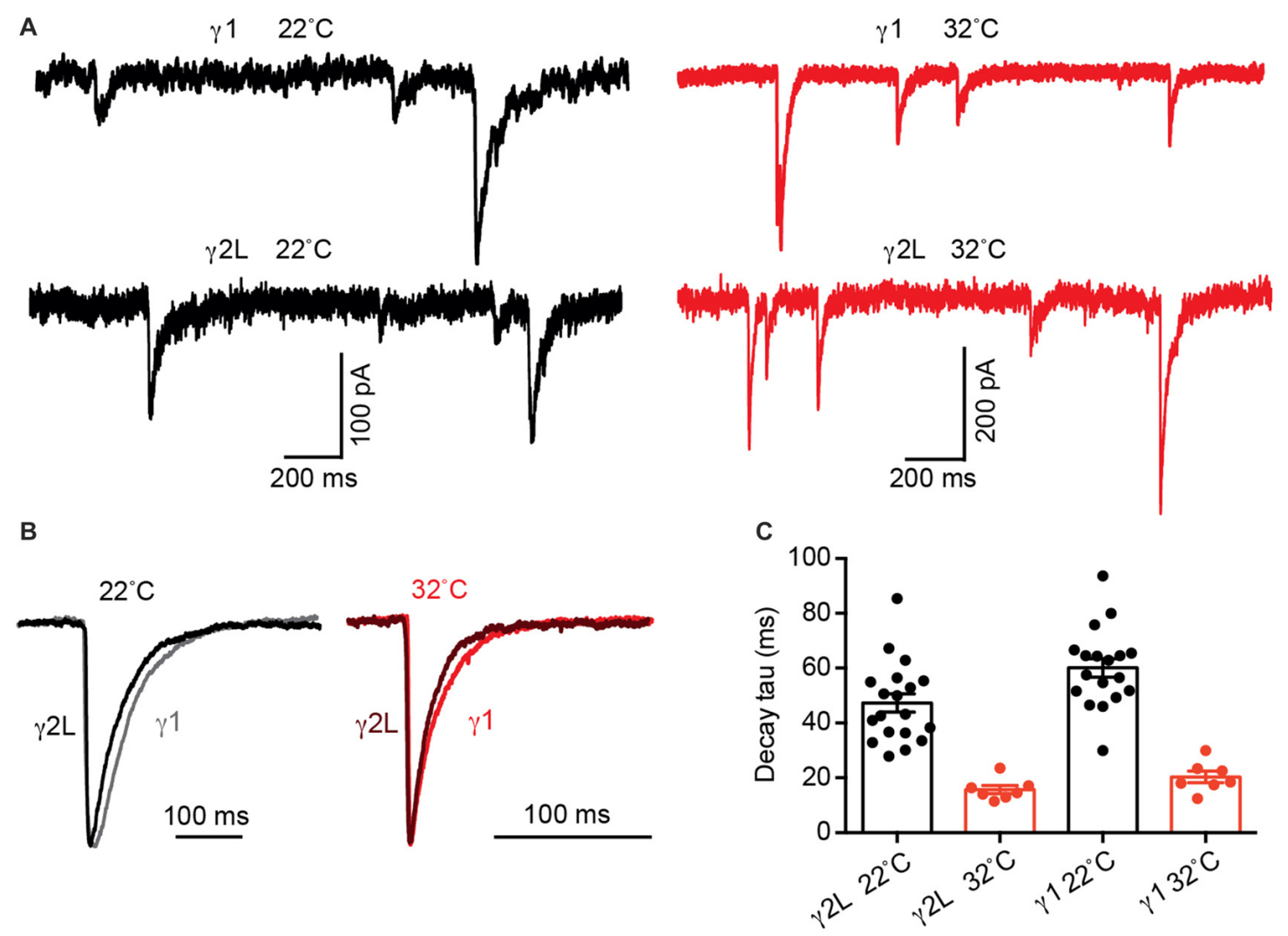

FIGURE 3 | Increasing temperature accelerated $\alpha 2 \beta 2 \gamma 2 \mathrm{~L}$ - and $\alpha 2 \beta 2 \gamma 1$-mediated IPSC decay time constants to an equivalent extent. (A) Sample recordings of IPSCs at 22 and $32^{\circ} \mathrm{C}$ from co-cultured HEK293 cells expressing $\alpha 2 \beta 2 \gamma 2 \mathrm{~L}$ and $\alpha 2 \beta 2 \gamma 1$ GABA $\mathrm{Rs}$ showing increased amplitude and accelerated IPSC decay at higher temperature. (B) Averaged IPSC waveforms from indicated receptors at $22^{\circ} \mathrm{C}$ and $32^{\circ} \mathrm{C}$. (C) For both receptor types, the mean IPSC decay time constant was accelerated three fold by the $10^{\circ} \mathrm{C}$ temperature increase, indicating that the difference in the IPSC decay rate is dominated by the receptor gating properties and not by the GABA diffusion rate.

or $\gamma 2 \mathrm{~L}^{\mathrm{T} 349 \mathrm{~L}-\mathrm{mEos} 2}$ subunits in real time. Fusion of the mEos2 fluorescent protein to the $\gamma$ subunit extracellular domain allowed us to observe the ensemble of receptors in the green channel and to track the movement of individual receptors after converting mEos 2 to its red form. In addition, in a subset of experiments we also tagged the $\alpha 2$ subunit with the $\mathrm{pH}$-sensitive GFP ( $\mathrm{SEpH}$ ); this allowed us to visualize the receptors in green even after mEos 2 had been converted to its red form.

The splitting, merging and reshaping of receptor clusters could be followed on the scale of minutes, and did not depend on the receptor isoform. Figure 5A shows a snapshot of receptor distribution on the cell membrane of a HEK293 cell transfected with $\alpha 2^{\mathrm{SEpH}} \beta 2 \gamma 2 \mathrm{~L}^{\mathrm{mEos} 2} \mathrm{GABA}_{\mathrm{A}}$ Rs. The inset shows another snapshot taken 2 min later, where two representative clusters (arrow, Figure 5A) can be seen to have merged. It is apparent that single receptors are mobile over that time period and move between both clusters (white arrow in Figure 5B). In addition, single $\mathrm{GABA}_{\mathrm{A}}$ Rs also moved within distinct regions as suggested by the many clusters that remained unaltered (colored arrows in in Figure 5B). Addition of fluorescent protein to the $\gamma$ subunit did not change the decay rates of spontaneous IPSCs mediated by $\mathrm{GABA}_{\mathrm{A}} \mathrm{Rs}$ (Figure 5C). In neurons, $\mathrm{GABA}_{\mathrm{A}} \mathrm{Rs}$ containing the $\gamma 2 \mathrm{~L}$ subunit interact with the scaffolding protein gephyrin, which is also endogenously expressed in HEK293 cells. However, in HEK293 cells we only observed limited co-localization of $\alpha 2 \beta 2 \gamma 2 \mathrm{~L}$ receptors and gephyrin (Figure 5D).

Overall, $\gamma 1$-containing receptors were more mobile than those containing $\gamma 2 \mathrm{~L}$ subunits. At $32^{\circ} \mathrm{C}$ the fraction of $\alpha 2 \beta 2 \gamma 1^{\mathrm{mEos} 2}$ $\mathrm{GABA}_{\mathrm{A}}$ Rs undergoing free diffusion or changing domains was $28 \pm 4 \%$, compared to only $12.0 \pm 0.4 \%$ of $\alpha 2 \beta 2 \gamma 2 \mathrm{~L}^{\mathrm{mEos} 2}$ $\mathrm{GABA}_{\mathrm{A}}$ Rs (over 2000 trajectories from a minimum of 10 cells per transfection type). GABA $\mathrm{A}_{\mathrm{A}}$ Rs containing the T349L mutation in the $\gamma 2 \mathrm{~L}$ subunits behaved similarly to $\alpha 2 \beta 2 \gamma 2 \mathrm{~L}^{\text {mEos } 2} \mathrm{GABA}_{\mathrm{A}} \mathrm{Rs}$ and had $11.7 \pm 0.4 \%$ of the trajectories located outside of single domains. Single $\mathrm{GABA}_{\mathrm{A}} \mathrm{R}$ trajectories were further analyzed in terms of MSD to determine the characteristic diffusion coefficient. Figure 5E shows representative MSD vs. time plots for the different receptor subunit combinations. All MSD plots exhibited a negative deviation from a straight line, indicating confinement of the receptors in the subdomains.

At RT, the average diffusion coefficient for $\alpha 2 \beta 2 \gamma 2 \mathrm{~L}^{\mathrm{mEos} 2}$ GABA $_{\mathrm{A}} \mathrm{Rs}$ was $(1.6 \pm 0.5) \times 10^{-2} \mathrm{\mu m}^{2} / \mathrm{s}$ (Figure $5 \mathrm{~F}$ ), 

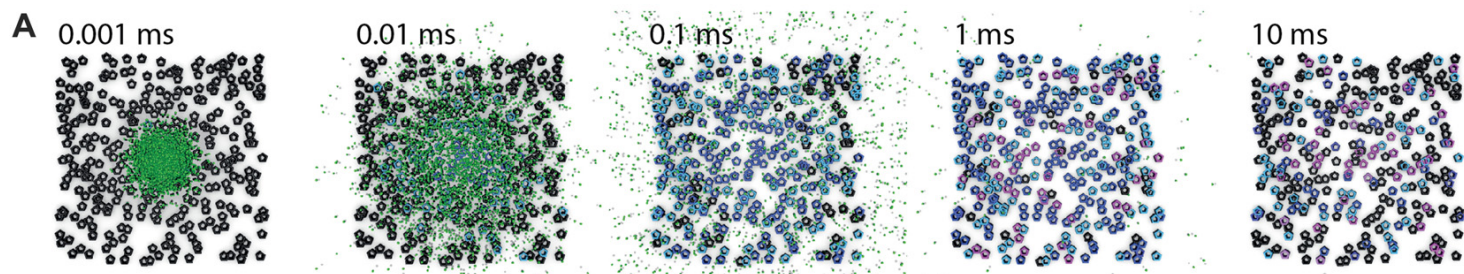

Key: $\quad \mathrm{GABA}$

Unbound $G A B A_{A} R$

- Monoligand $\mathrm{GABA}_{\mathrm{A}} \mathrm{R}$

Diligand $G A B A_{A} R$

Open $\mathrm{GABA}_{A} \mathrm{R}$

B Cluster size:

$200 \mathrm{~nm}$

$400 \mathrm{~nm}$

$800 \mathrm{~nm}$

$1600 \mathrm{~nm}$
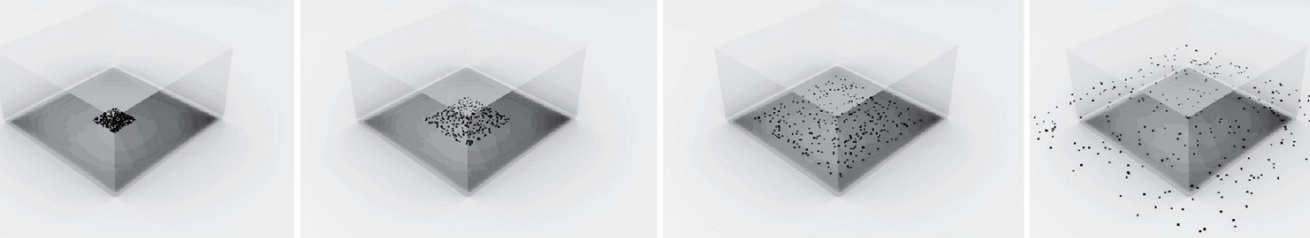

C

Simulated channel openings

D Peak-scaled

Dixon et al., 2014
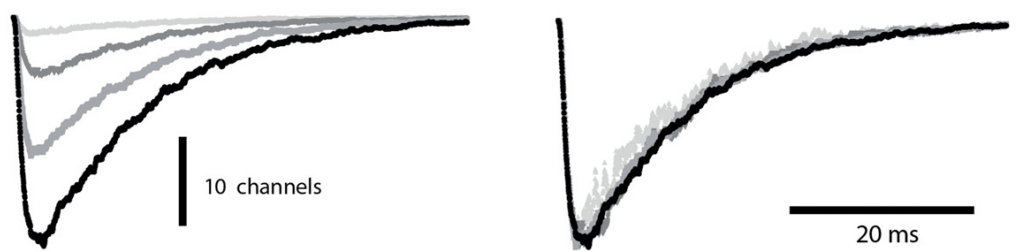

Petrini et al., 2011
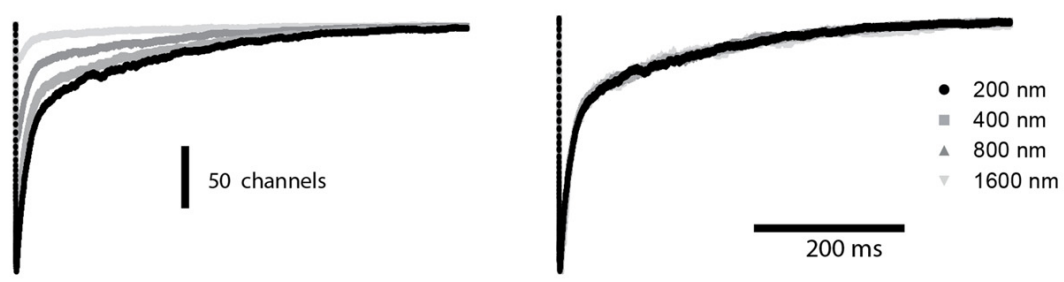

FIGURE 4 | Monte Carlo simulations of synaptic function. The default parameters used to set up the simulations are provided in Table 1. (A) Top view of a simulation of the postsynaptic density with the presynaptic terminal removed. A total 300 receptors are spread across a $200 \times 200 \mathrm{~nm}$ square, and 3000 GABA molecules were released from a point source at time 0 . To illustrate the time required for GABA to leave the cleft, the slowest diffusion constant we tested $\left(0.1 \mu \mathrm{m}^{2} / \mathrm{ms}\right)$ is shown. Diffusion of GABA out of the synaptic cleft occurs rapidly, within $0.01 \mathrm{~ms}$, meaning that very few if any extrasynaptic binding events are likely to slow the decay time of IPSCs. (B) The same model, with the 300 receptors spread out across increasingly large postsynaptic densities. The presynaptic terminal is transparent. (C) Sample waveforms generated by the simulation shown in (B) with a realistic diffusion constant of $0.3 \mu \mathrm{m}^{2} / \mathrm{ms}$. Peak scaled waveforms show that the IPSC decay time course is unaffected by the receptor clustering density. (D) As for (C), but this time using an alternative receptor model that included mono-liganded openings and co-operative agonist binding.

whereas the diffusion coefficient of $\alpha 2 \beta 2 \gamma 1^{\mathrm{mEos} 2} \mathrm{GABA}_{\mathrm{A}} \mathrm{Rs}$ was $(5.5 \pm 0.8) \times 10^{-2} \mu \mathrm{m}^{2} / \mathrm{s}$, which is significantly higher (Student $t$-test, $P<0.0001)$. Moreover, the $\alpha 2 \beta 2 \gamma 2 \mathrm{~L}^{\mathrm{T} 349 \mathrm{~L} / \mathrm{mEos} 2}$ $\mathrm{GABA}_{\mathrm{A}} \mathrm{Rs}$, which exhibit similar IPSC decay rates to $\alpha 2 \beta 2 \gamma 1 \mathrm{GABA}_{\mathrm{A}} \mathrm{Rs}$, diffused at a similar rate to the $\alpha 2 \beta 2 \gamma 2 \mathrm{~L}^{\mathrm{mEos} 2} \mathrm{GABA}_{\mathrm{A}} \mathrm{Rs}$, with a mean diffusion coefficient of $(1.6 \pm 0.3) \times 10^{-2} \mu \mathrm{m}^{2} / \mathrm{s}$. With the increase in temperature to $32^{\circ} \mathrm{C}$, the mobility of single receptors increased 1.9 -fold for 

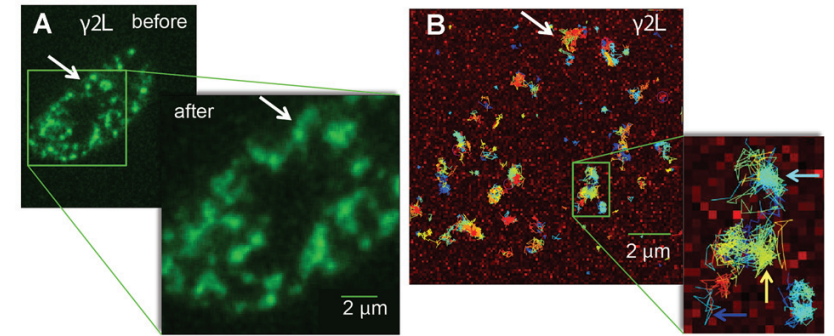

C

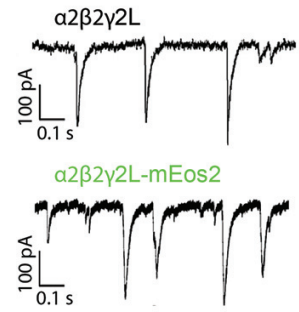

D
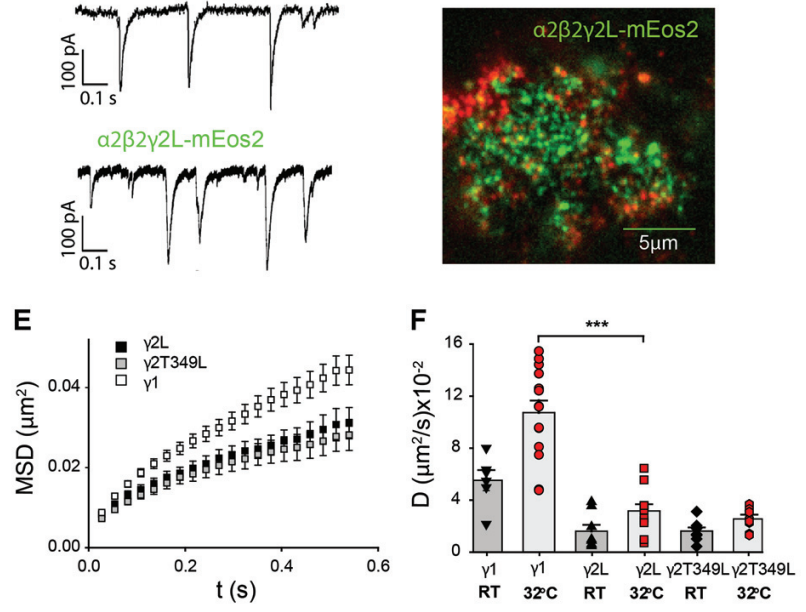

FIGURE 5 | Single-particle tracking of GABA $_{A}$ Rs expressed non-synaptically in HEK293 cells. (A) Total internal reflection (TIRF) image of the bottom

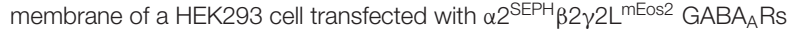
and imaged before and after the single-particle tracking experiment shown in (B). The $\mathrm{GABA}_{A}$ Rs are organized in domains whose restructuring occurs over several minutes (white arrow). (B) Single-particle tracking photoactivation localization microscopy (sptPALM) trajectories of single $\mathrm{GABA}_{\mathrm{A}} \mathrm{Rs}$ show that their movement is confined within domains (light blue arrow). A small number of channels can move between domains (yellow arrow) or diffuse freely (dark blue arrow). For clarity only a subset of trajectories is shown. (C) An example of spontaneous synaptic currents recorded from a HEK cell in co-culture expressing $\alpha 2 \beta 2 \gamma 2 \mathrm{~L}-\mathrm{mE}$ Es 2 . The receptors formed with labeled $\gamma 2 \mathrm{~L}$ subunit are functional and their synaptic currents are similar to those of wild-type receptors. (D) $\mathrm{GABA}_{A} \mathrm{Rs}$ (green) are only partially co-localized with endogenous gephyrin (red) in HEK 293 cells. (E) Averaged ( \pm SEM) mean-squared displacement (MSD) vs. time plots for receptors incorporating the indicated mEos2-tagged $\gamma$ subunits recorded at room temperature (RT). All MSD curves reflect confinement of receptors within nanodomains. (F) Average diffusion coefficient of receptors containing mEos2-tagged $\gamma 1$, $\gamma 2$ and $\gamma 2 \mathrm{~L}^{\mathrm{T} 349 \mathrm{~L}}$ subunits measured at RT or $32^{\circ} \mathrm{C}$. ${ }^{* * *} P<0.001$.

$\alpha 2 \beta 2 \gamma 1$ and $\left.\alpha 2 \beta 2 \gamma 2 \mathrm{~L} \mathrm{GABA}_{\mathrm{A}} \mathrm{Rs} ; 10.7 \pm 0.9\right) \times 10^{-2} \mu \mathrm{m}^{2} / \mathrm{s}$ and $(3.5 \pm 0.1) \times 10^{-2} \mu \mathrm{m}^{2} / \mathrm{s}$, respectively) and 1.5 times for $\alpha 2 \beta 2 \gamma 2 \mathrm{~L}^{\mathrm{T} 349 \mathrm{~L}} \mathrm{GABA}_{\mathrm{A}} \mathrm{Rs}$ (to a value of $(2.6 \pm 0.3) \times 10^{-2} \mu \mathrm{m}^{2} / \mathrm{s}$; Figure $5 \mathrm{~F}$ ). These values are similar to those previously reported for $\alpha 2$-containing $\mathrm{GABA}_{\mathrm{A}}$ Rs in hippocampal neurons (Hausrat et al., 2015).

Because our sptPALM experiments were performed in the TIRF configuration with the penetration depth ranging from $100 \mathrm{~nm}$ to $120 \mathrm{~nm}$, it is possible that some of the imaged $\mathrm{GABA}_{\mathrm{A}} \mathrm{Rs}$ may have been located intracellularly. To address this, we replaced mEos2, which was inserted near the $\mathrm{N}$-terminus in the extracellular part of the $\gamma$ subunit, with
SEpH and used Alexa 647 conjugated anti-GFP antibodies for single-particle tracking in uPAINT experiments (Giannone et al., 2010). This method ensured that we imaged only $\mathrm{GABA}_{\mathrm{A}} \mathrm{Rs}$ expressed at the cell surface. We obtained a diffusion coefficient of $(10.7 \pm 0.9) \times 10^{-2} \mu \mathrm{m}^{2} / \mathrm{s}$ for $\alpha 2 \beta 2 \gamma 1^{\mathrm{SEPH}} \mathrm{GABA}_{\mathrm{A}}$ Rs and $(3.2 \pm 0.5) \times 10^{-2} \mu \mathrm{m}^{2} / \mathrm{s}$ for $\alpha 2 \beta 2 \gamma 2 \mathrm{~L}^{\mathrm{SEPH}} \mathrm{GABA}_{\mathrm{A}}$ Rs at $32^{\circ} \mathrm{C}$, in excellent agreement with the results obtained using mEos 2 and with previously published results that quantified the diffusion rate of $\gamma 2$-containing $\mathrm{GABA}_{\mathrm{A}}$ Rs in hippocampal neurons (Bannai et al., 2009). We therefore conclude that the sptPALM method successfully measured the mobility of $\mathrm{GABA}_{\mathrm{A}}$ Rs inserted in the plasma membrane.

In order to examine the mobility of $\mathrm{GABA}_{\mathrm{A}}$ Rs relative to the synapse, we labeled neuronal presynaptic sites with Oyster 650-conjugated synaptotagmin antibodies, and analyzed single-channel trajectories that originated within labeled regions (Figure 6A). At $32^{\circ} \mathrm{C}, \alpha 2 \beta 2 \gamma 1^{\mathrm{mEos} 2} \mathrm{GABA}_{\mathrm{A}}$ Rs located at the synapse exhibited an average diffusion coefficient of $(2.7 \pm 0.5) \times 10^{-2} \mu \mathrm{m}^{2} / \mathrm{s}(n=11)$, much slower than in extrasynaptic regions $(P<0.0001$, Student $t$-test). The diffusion rates of synaptic $\mathrm{GABA}_{\mathrm{A}}$ Rs containing $\gamma 1$ or $\gamma 2 \mathrm{~L}$ subunits were similar $\left(\mathrm{D}_{\alpha 2 \beta 2 \gamma 2 \mathrm{mEos} 2}=(2.6 \pm 0.9) \times 10^{-2} \mu \mathrm{m}^{2} / \mathrm{s}, n=12\right)$. A comparison of MSD curves calculated from synaptic and extrasynaptic regions for $\gamma 1$ - and $\gamma 2 \mathrm{~L}$-containing receptors is shown in Figures 6B,C. Smaller MSD indicates that the motion of $\mathrm{GABA}_{\mathrm{A}} \mathrm{Rs}$ is additionally constrained at the synapse formed between neurons and HEK293 cells. We calculated an average size of the compartments within which $\mathrm{GABA}_{\mathrm{A}} \mathrm{R}$ movement was constricted and found that $\alpha 2 \beta 2 \gamma 1^{\mathrm{mEos} 2}$ receptors diffused within larger domains in extrasynaptic regions of HEK293 cells compared to $\alpha 2 \beta 2 \gamma 2 \mathrm{~L}^{\mathrm{mEos} 2} \mathrm{GABA}_{\mathrm{A}} \mathrm{Rs}(0.70 \pm 0.02 \mu \mathrm{m}$ and $0.29 \pm 0.05 \mu \mathrm{m}$ respectively, $P<0.0001$, Student $t$-test). However, at the synapse both receptor types moved within the domains similar in size; $\alpha 2 \beta 2 \gamma 1^{\mathrm{mEos} 2}$ and $\alpha 2 \beta 2 \gamma 2 \mathrm{~L}^{\mathrm{mEos} 2}$ confinement size was $0.27 \pm 0.03 \mu \mathrm{m}$ and $0.26 \pm 0.04 \mu \mathrm{m}$, respectively (Figure 6D). In addition, $\gamma 1$ - and $\gamma 2$-containig $\mathrm{GABA}_{\mathrm{A}} \mathrm{Rs}$ formed similarly spaced synapses. The mean distance between synaptic clusters was $3.9 \pm 0.4 \mu \mathrm{m}$ and $4.0 \pm 0.5 \mu \mathrm{m}$ for $\alpha 2 \beta 2 \gamma 1^{\mathrm{mEos} 2}$ and $\alpha 2 \beta 2 \gamma 2 \mathrm{~L}^{\mathrm{mEos} 2}$ respectively (Supplementary Figure S3A). This result supports the conclusion that differential clustering of receptors cannot explain the differences in IPSC decay rate and provides the first direct evidence for the localization of $\gamma 1$-containing $G_{A B A}$ Rs at synapses.

\section{Organization of $\gamma 1$ - and $\gamma 2$-Containing GABA $_{A}$ Rs in Neurons}

While artificial GABAergic synapses allow us to measure IPSCs produced by $\mathrm{GABA}_{\mathrm{A}} \mathrm{R}$ isoforms with defined subunit compositions, they may lack some of the postsynaptic intracellular proteins found in neurons and may therefore not accurately recapitulate the $\mathrm{GABA}_{\mathrm{A}} \mathrm{R}$ mobility and clustering properties as observed in vivo. To investigate this, we expressed $\gamma 1^{\mathrm{SEPH}}, \gamma 2 \mathrm{~L}^{\mathrm{SEpH}}$ and $\gamma 2 \mathrm{~L}^{\mathrm{T} 349 \mathrm{~L}-\mathrm{SEpH}}$ subunits in cultured cortical neurons and studied their organization and 

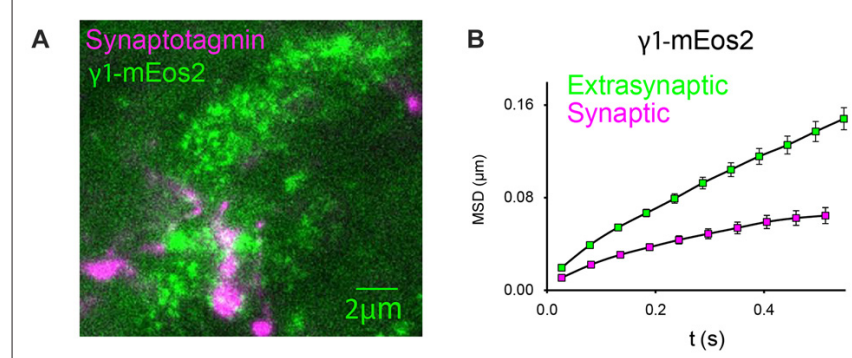

C

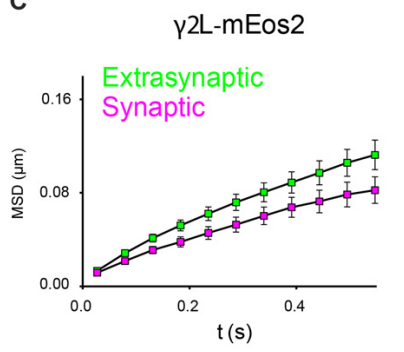

D

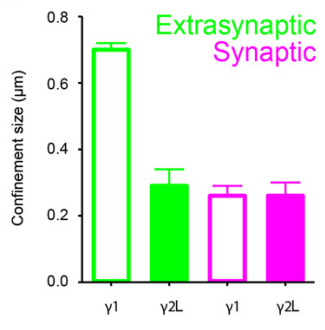

FIGURE 6 | In artificial synapses, $\alpha 2^{\mathrm{SEPH}} \beta 2 \gamma 2 \mathrm{~L}^{\mathrm{mEOs} 2} \mathrm{GABA}_{A}$ Rs diffuse more slowly within synaptic regions. (A) Immunolabeling of synaptotagmin-positive presynaptic terminals of cortical neurons (magenta) and a HEK293 cell expressing $\alpha 2^{\mathrm{SEPH}} \beta 2 \gamma 1^{\mathrm{mEos} 2} \mathrm{GABA}_{A}$ Rs at $32^{\circ} \mathrm{C}$ (green). Clusters of $\mathrm{GABA}_{A} R s$ are visible at the synapse. $(\mathbf{B}, \mathbf{C})$ Mean MSD vs. time plots for $\gamma 1$ - and $\gamma 2$-containing $\mathrm{GABA}_{\mathrm{A}} \mathrm{Rs}$ obtained from single-channel trajectories within synaptotagmin-labeled regions show stronger confinement and slower diffusion (green squares) compared to those in other parts of the cell membrane where synaptic contacts are not formed (magenta squares). (D) Average confinement size in extrasynaptic regions (green) and at synapses (magenta).

dynamics in synaptic and extrasynaptic regions at $36^{\circ} \mathrm{C}$. We used Alexa-647 conjugated anti-GFP antibodies to stochastically label single $\mathrm{GABA}_{\mathrm{A}} \mathrm{Rs}$ and Oyster 560-conjugated antibodies to highlight synaptotagmin-rich presynaptic regions. This approach allowed us to create a map of the receptor positions in an uPAINT experiment.

$\mathrm{GABA}_{\mathrm{A}}$ Rs containing $\gamma 2 \mathrm{~L}$ subunits formed clusters in cortical neurons (Figure 7A, left panel). As previously described for $\gamma 2 \mathrm{~L}$-containing $\mathrm{GABA}_{\mathrm{A}}$ Rs (Bannai et al., 2009; Choquet and Triller, 2013), uPAINT revealed a population that diffused freely and a population whose movement was strongly confined within clusters, some of which were in close proximity to synaptotagmin-labeled presynaptic sites (Figure 7A, white puncta, middle panel). Trapping of receptors in synaptic regions and their escape was also evident (Figure 7A, yellow arrows). We classified single-channel trajectories as extrasynaptic or synaptic based on their proximity to presynaptic terminals. $\mathrm{GABA}_{\mathrm{A}} \mathrm{Rs}$ were considered to be localized at the synapse if they were found in clusters that overlapped with synaptotagmin labeling (Figure 7A, magenta arrow, right panel) and extrasynaptic otherwise. Similar analysis were performed on $\gamma 1$ and $\gamma 2^{\mathrm{T} 349 \mathrm{~L}}$ subunits (Figures 7B,C). As expected, the average MSD of synaptic $\gamma 2 \mathrm{~L}$-containing $\mathrm{GABA}_{\mathrm{A}} \mathrm{Rs}$ was smaller than that of extrasynaptic $\mathrm{GABA}_{\mathrm{A}} \mathrm{Rs}$, consistent with decreased lateral mobility due to the interaction with scaffolding proteins (Figures 7D,E, blue circles). From MSD plots, we calculated

that synaptic $\mathrm{GABA}_{\mathrm{A}} \mathrm{Rs}$ containing $\gamma 2 \mathrm{~L}$ moved within regions whose size was on average $(0.18 \pm 0.03) \mu \mathrm{m}$ (Figure $7 \mathbf{F}$, blue bar).

$\gamma 1$-containing $\mathrm{GABA}_{\mathrm{A}} \mathrm{Rs}$ formed clusters at both synaptic and extrasynaptic sites, but were overall highly mobile, spanning larger distances between clusters than $\gamma 2 \mathrm{~L}$-containing receptors (Figure 7B). Single-channel trajectories showed that $\gamma 1$-containing receptors had a higher frequency of exchange between synaptic and perisynaptic populations than $\gamma 2 \mathrm{~L}$-containing $\mathrm{GABA}_{\mathrm{A}} \mathrm{Rs}(13.2 \pm 1.2 \%$, compared to $7 \pm 1 \%$ during an average imaging time of $2.5 \mathrm{~min}$ ). In addition, many $\gamma 1$-containing receptors visited regions of the neuronal plasma membrane close to synaptotagmin-rich areas but did not dock at the synapse (e.g., Figure $\mathbf{7 B}$, turquoise arrow). The increased mobility of $\gamma 1$-containing receptors gave rise to the slope of the extrasynaptic MSD curve, which was steeper than that for $\gamma 2 \mathrm{~L}$-containing $\mathrm{GABA}_{\mathrm{A}}$ Rs (Figure $7 \mathrm{D}$, white circles). However, the $\gamma 1$-containing receptors localized at the synapse showed similar confined motion to $\mathrm{GABA}_{\mathrm{A}} \mathrm{Rs}$ containing $\gamma 2 \mathrm{~L}$ subunits (Figure 7E, Fs, white circles and bar).

The overall shape of the average MSD curve depends on the proportion of clustered receptors with constricted movement, as well as the diffusion coefficients and confinement size. In an attempt to decouple these effects, we plotted a histogram of instantaneous diffusion coefficients obtained from all trajectories for neurons transfected with $\gamma 1$ or $\gamma 2 \mathrm{~L}$ subunits. Both distributions were bimodal and the range of diffusion coefficients was similar. $\mathrm{GABA}_{\mathrm{A}} \mathrm{Rs}$ containing $\gamma 2 \mathrm{~L}$ subunits had the less mobile population dominating the distribution of diffusion coefficients (Figure 7G, blue squares). GABA ${ }_{A} R$ containing $\gamma 1$ subunits had a larger fast moving population (Figure $\mathbf{7 H}$, charcoal squares) which increased the MSD of extrasynaptic receptors but did not affect the size of synaptic clusters (Figures 7E,F).

When we expressed $\gamma 2 \mathrm{~L}^{\mathrm{T} 349 \mathrm{~L}}$, a subunit that switches IPSC kinetics from $\alpha 2 \beta 2 \gamma 2 \mathrm{~L}$ to $\alpha 2 \beta 2 \gamma 1$, the $\mathrm{GABA}_{\mathrm{A}} \mathrm{Rs}$ exhibited motion similar to the $\gamma 2 \mathrm{~L}$-containing receptors. This is illustrated in Figure $\mathbf{7 C}$, where the correlation between the receptors and synaptotagmin is prominent and the fraction of freely diffusing channels is smaller than that of $\gamma 1$-containing GABA $\mathrm{A}_{\mathrm{A}}$ s. The MSD plots, synaptic confinement size and the distribution of instantaneous diffusion coefficients confirmed that the movement of $\gamma 2 \mathrm{~L}^{\mathrm{T} 349 \mathrm{~L}}$-containing receptors was virtually indistinguishable from that of $\gamma 2 \mathrm{~L}$-containing $\mathrm{GABA}_{\mathrm{A}}$ Rs (Figures 7E-G, red symbols).

As we did not focus on a specific neuron type, in Figure 7I we compared the cell-to-cell variation in motion of $\mathrm{GABA}_{\mathrm{A}} \mathrm{Rs}$ containing different $\gamma$ subunits by calculating the diffusion coefficients from the averaged MSD curves. As expected, in neurons expressing the $\gamma 1$ subunit, the measured diffusion coefficients of $\mathrm{GABA}_{\mathrm{A}} \mathrm{Rs}$ was significantly higher than that in the receptors expressing $\gamma 2 \mathrm{~L}$ or $\gamma 2 \mathrm{~L}^{\mathrm{T} 349 \mathrm{~L}}$ subunits (Figure 7I). However, at synaptic sites, the movement of $\gamma 1$-containing $\mathrm{GABA}_{\mathrm{A}} \mathrm{Rs}$ was reduced (Figure 7J). Although not statistically significant, a trend toward higher diffusion coefficients at synaptic sites is a consequence of a higher 

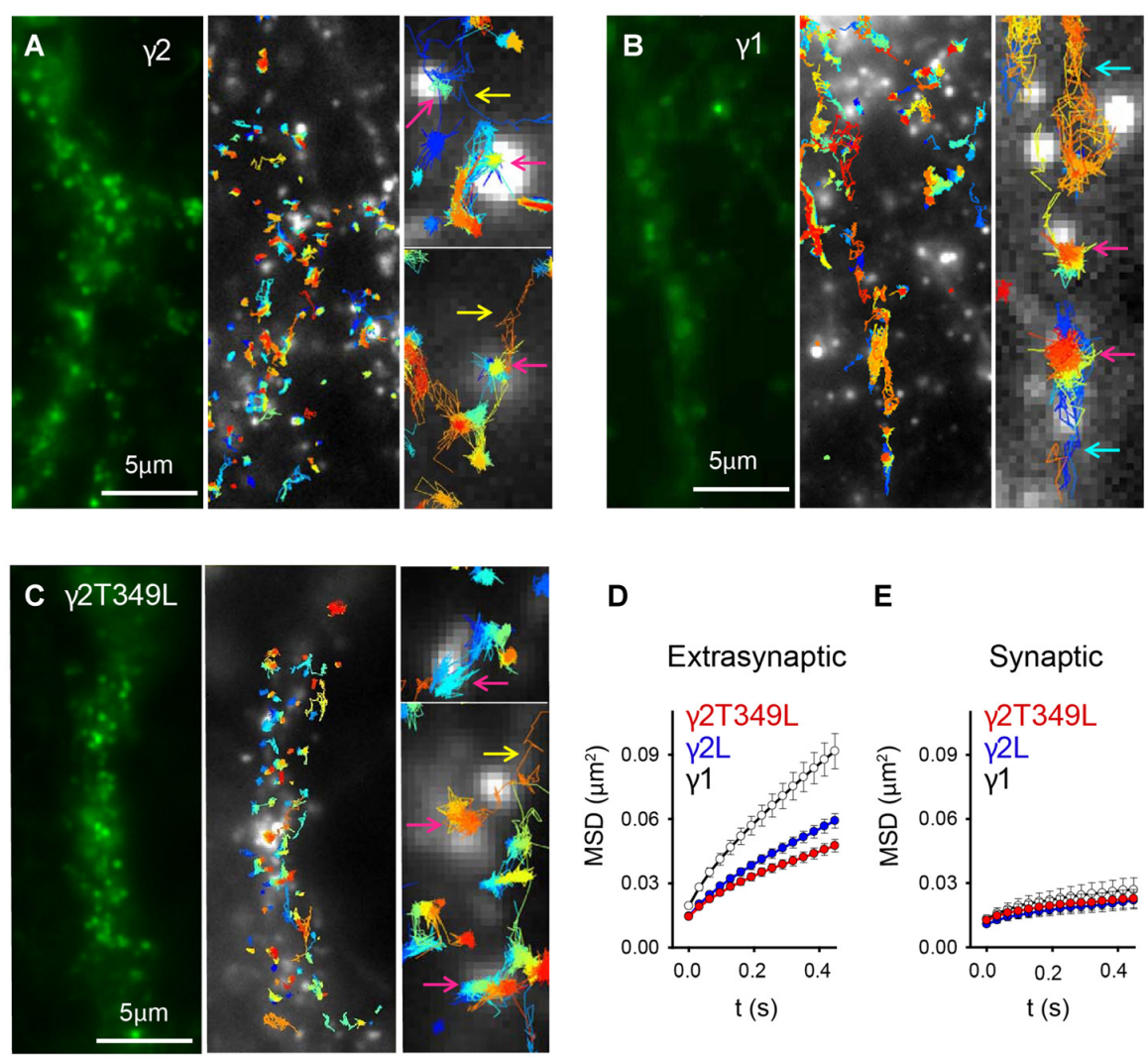

E

$\mathbf{F}$

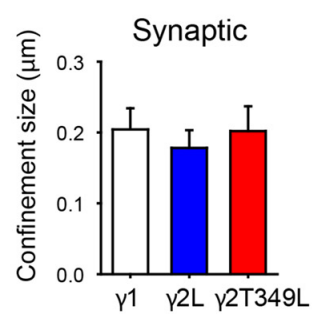

I

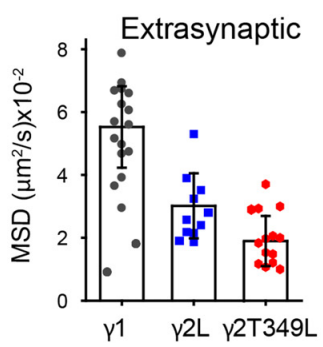

G

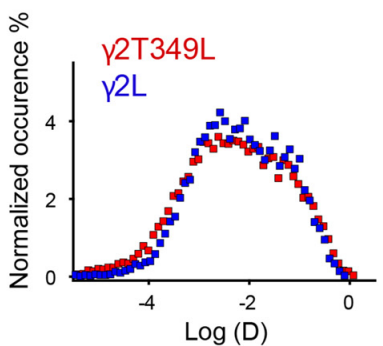

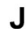

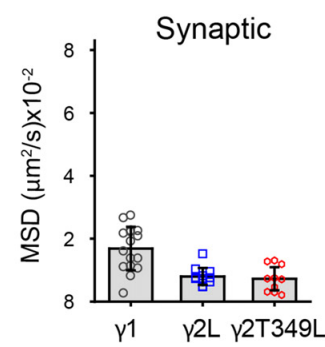

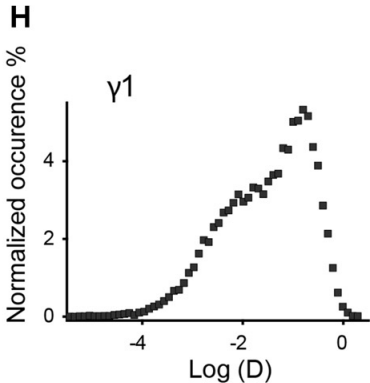

K

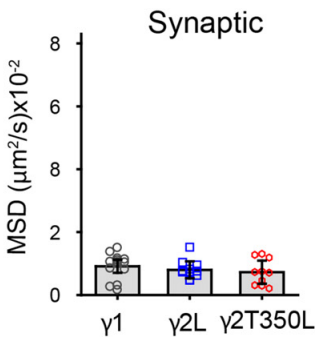

FIGURE 7 | Universal point accumulation for imaging in nanoscale topography (uPaint) imaging in neurons reveals differences in the mobility of GABA ${ }_{A}$ Rs with different $\gamma$ subunits. (A-C) Examples of $\gamma 2 \mathrm{~L}, \gamma 1$ and $\gamma 2 \mathrm{~L}^{\top 349 \mathrm{~L}}$ subunit organization in cortical neurons. The left panels depict raw images of superecliptic pHluorin (SEpH)-labeled subunits. In uPAINT experiments single GABA $\mathrm{Rs}$ are localized in respect to presynaptic regions labeled with synaptotagmin (light puncta in center panels). Zoomed regions in the right panels show examples of the receptors, which are freely diffusing, entering or leaving synaptic regions, or confined at the synapse (turquoise, yellow and magenta arrows, respectively). The width of the zoomed in regions is $1 \mu \mathrm{m}$. (D) Averaged ( \pm SEM) MSD vs. time plots for extrasynaptic receptors. (E) Averaged ( \pm SEM) MSD plot showing that mobility of $\gamma 1$ - and $\gamma 2$ L-containing GABA $A_{A}$ is similar at synapses. (F) Average ( \pm SEM) confinement size of synaptic receptors. $(\mathbf{G}, \mathbf{H})$ Distribution of instantaneous diffusion coefficients of $\mathrm{GABA}_{\mathrm{A}} \mathrm{RS}$ 


\section{FIGURE 7 | Continued}

containing $\gamma 2, \gamma 2 \mathrm{~T} 349 \mathrm{~L}$ or $\gamma 1$ subunits (red, blue and charcoal squares respectively). The distribution is bimodal for all receptors, indicating clustered, less mobile and freely diffusive populations of receptors. For $\gamma 1$-containing receptors, the peak of the distribution is right shifted, indicating a larger number of freely diffusing receptors. (I) A plot showing neuron-to-neuron variability in diffusion coefficients as calculated from the average MSD curve per neuron. (J) Same as (I) but only synaptic receptors are included. There is no statistical difference between diffusion coefficients. (K) Same as $\mathbf{( J )}$ but the receptors that moved in or out of synaptic regions were excluded from analysis.

exchange rate between synaptic and extrasynaptic $\gamma 1$-containing $\mathrm{GABA}_{\mathrm{A}}$ Rs compared to $\gamma 2 \mathrm{~L}$ - and $\gamma 2 \mathrm{~L}^{\mathrm{T} 349 \mathrm{~L}}$-containing receptors (Figure 7J, black circles). When we excluded receptors that moved in or out of synaptic regions, the $\gamma 1$-containing $\mathrm{GABA}_{\mathrm{A}} \mathrm{Rs}$ moved as slowly as those containing $\gamma 2 \mathrm{~L}$ subunits (Figure $7 \mathbf{K}$ ). In addition, we measured absolute distances between synaptic clusters along neurites and found that $\gamma 1$ and $\gamma 2$-containing $\mathrm{GABA}_{\mathrm{A}} \mathrm{Rs}$ formed synapses at similar distances $(3.9 \pm 0.3 \mu \mathrm{m}$ and $4.1 \pm 0.5 \mu \mathrm{m}$ for synaptic clusters containing $\gamma 1$ or $\gamma_{2}$ subunits respectively, Supplementary Figure S3B). Taken together, these results strongly suggest that the difference in IPSC kinetics cannot be explained by changes in flux, residence time or clustering of the receptors at the synapse. Rather, we infer that $\gamma 1$-containing receptors exhibit slower synaptic current decay due to differential inherent gating dynamics when localized at neuronal synapses.

\section{DISCUSSION}

We sought to understand why, when expressed in artificial synapses, IPSCs mediated by $\alpha 2 \beta 2 \gamma 1 \mathrm{GABA}_{\mathrm{A}} \mathrm{Rs}$ exhibit significantly slower decay kinetics than those mediated by $\alpha 2 \beta 2 \gamma 2 \mathrm{~L} \mathrm{GABA}_{\mathrm{A}}$ Rs. Given that the two receptors exhibit similar inherent opening and closing rates when isolated from the synapse (Dixon et al., 2014), we initially hypothesized that the difference in their IPSC decay rates was due to a non-conserved structural element in the large intracellular domain. We identified a single amino acid (Thr349) in the middle of the $\gamma 2 \mathrm{~L}$ subunit cytoplasmic loop that was solely responsible for the differential IPSC decay kinetics. That is, $\alpha 2 \beta 2 \gamma 2 \mathrm{~L}^{\mathrm{T} 349 \mathrm{~L}}$ receptors exhibited an IPSC decay rate that was $\alpha 2 \beta 2 \gamma 1$-like, whereas the converse mutation to the $\gamma 1$ subunit $\left(\gamma 1^{\mathrm{L} 353 \mathrm{~T}}\right)$ had the opposite effect. Although Thr349 can be phosphorylated by CaMKII in isolated protein experiments (McDonald and Moss, 1994), replacing Thr349 with phosphomimetic or other residues could not replicate the effect of the T349L mutation. Thus, phosphorylation of Thr349 does not explain the differential kinetics.

We next tested whether the difference in IPSC kinetics was due to an altered propensity of the two $\mathrm{GABA}_{\mathrm{A}} \mathrm{R}$ subtypes to cluster at postsynaptic densities. At both glutamatergic and GABAergic synapses delayed neurotransmitter access to extrasynaptic or perisynaptic receptors can lead to synaptic currents with slower rise and decay times
(Lozovaya et al., 1999; Oláh et al., 2009; Wu et al., 2012). This mechanism can be revealed by blocking GABA reuptake (Gonzalez-Burgos et al., 2009). However, blocking re-uptake of GABA via GAT-1 inhibition had no effect on the rise or decay times of IPSCs mediated by $\alpha 2 \beta 2 \gamma 1$ or $\alpha 2 \beta 2 \gamma 2 \mathrm{~L} \mathrm{GABA}_{\mathrm{A}}$ Rs. This could mean that transport is not important at neuronHEK293 cell synapses, or that IPSC decay at these synapses is determined by the inherent properties of the channels, without opportunities for late-binding channels to slow down the event. Monte Carlo simulations showed that the slow IPSC decay rate at $\alpha 2 \beta 2 \gamma 1$ synapses cannot be explained by the diffusion of GABA to distant receptors. Spreading receptors further away from the release site did not change IPSC decay kinetics, even when we modeled asynchronous release spread over $5 \mathrm{~ms}$ The peak of our IPSCs (both real and simulated) occurred after several milliseconds. In order for delayed binding at distant $\mathrm{GABA}_{\mathrm{A}}$ Rs to contribute to the decay time, new $\mathrm{GABA}_{\mathrm{A}}$ Rs would need to open after the peak, but this is inconsistent with the very short time that it takes for GABA to diffuse out of the cleft (Figure 3A).

In a final attempt to investigate the plausibility of reduced clustering as a mechanism for slow decay, we investigated whether $\alpha 2 \beta 2 \gamma 1$ and $\alpha 2 \beta 2 \gamma 2 \mathrm{~L} \mathrm{GABA}_{\mathrm{A}}$ Rs exhibited differences in clustering at synapses. In the plasma membrane of HEK293 cells devoid of artificial synaptic contacts, $\gamma 1$-containing $\mathrm{GABA}_{\mathrm{A}} \mathrm{Rs}$ diffused significantly more rapidly than $\gamma_{2} \mathrm{~L}$ containing $\mathrm{GABA}_{\mathrm{A}}$ Rs. In contrast to its effect on IPSC kinetics, the $\gamma 2 \mathrm{~L}^{\mathrm{T} 349 \mathrm{~L}}$ mutation had no effect on the receptor diffusion rate. However, in the regions where synaptic contacts were formed, $\gamma 1$-containing $\mathrm{GABA}_{\mathrm{A}}$ Rs were confined to the extent that their mobility was not significantly different to that of $\gamma 2 \mathrm{~L}$-containing $\mathrm{GABA}_{\mathrm{A}}$ Rs. The diffusion rates for $\gamma 2 \mathrm{~L}$-containing $\mathrm{GABA}_{\mathrm{A}} \mathrm{Rs}$ were similar to those measured previously for $\alpha 2$-containing $\mathrm{GABA}_{\mathrm{A}}$ Rs in neurons (Hausrat et al., 2015). Because the mobility of $\alpha 2 \beta 2 \gamma 1 \mathrm{GABA}_{\mathrm{A}} \mathrm{Rs}$ is significantly reduced in postsynaptic regions, we infer that clusters of $\alpha 2 \beta 2 \gamma 1 \mathrm{GABA}_{\mathrm{A}} \mathrm{Rs}$ are not displaced from the synapse.

In neurons, $\gamma 2 \mathrm{~L}$ - and $\gamma 2 \mathrm{~L}^{\mathrm{T} 349 \mathrm{~L}}$-containing $\mathrm{GABA}_{\mathrm{A}} \mathrm{Rs}$ both exhibited pronounced clustering, and the global distribution of diffusion coefficients was bimodal. $\mathrm{GABA}_{\mathrm{A}}$ Rs containing the $\gamma 1$ subunit formed clusters at the synapse and in extrasynaptic regions. In neurons, their diffusion coefficients also displayed a bimodal distribution, however, $\gamma 1$-containing receptors had larger fast-moving population and higher frequency of escape from clusters compared to $\gamma 2 \mathrm{~L}$-containing $\mathrm{GABA}_{\mathrm{A}} \mathrm{Rs}$. Considering the tagged $\gamma$ subunits transfected into neurons are likely to assemble with a range of endogenous $\alpha$ and $\beta$ subunits, our data from neurons and HEK293 cells correspond remarkably well. Three key features emerge from the pooled results. The first is that $\gamma 1$-containing $\mathrm{GABA}_{\mathrm{A}} \mathrm{Rs}$ have a more pronounced population of freely diffusing receptors in extrasynaptic regions. The second feature is that when $\gamma 1$-containing $\mathrm{GABA}_{\mathrm{A}} \mathrm{Rs}$ are found at synapses they exhibit similar confinement and diffusion rates to $\gamma 2 \mathrm{~L}$-containing $\mathrm{GABA}_{\mathrm{A}}$ Rs. The third feature is that the $\gamma 2 \mathrm{~L}^{\mathrm{T} 349 \mathrm{~L}}$ mutation has no effect on receptor mobility, despite its dramatic effect on 
IPSC kinetics. This last result effectively rules out the possibility that differences in diffusion rates of $\alpha 2 \beta 2 \gamma 1$ and $\alpha 2 \beta 2 \gamma 2 \mathrm{~L}$ $\mathrm{GABA}_{\mathrm{A}}$ Rs are responsible for the difference in their IPSC decay kinetics.

Neuronal $\gamma 2 \mathrm{~L}$-containing $\mathrm{GABA}_{\mathrm{A}} \mathrm{Rs}$ are found in cholesterol-rich regions and the mobility of both extrasynaptic and synaptic $\gamma 2 \mathrm{~L}$-containing $\mathrm{GABA}_{\mathrm{A}} \mathrm{Rs}$ is accelerated after cholesterol depletion (Renner et al., 2009). There is evidence that cholesterol is enriched in neuronal postsynaptic densities (Renner et al., 2009). Given that $\gamma 1$-containing receptors have larger flux at the synapse, they might be more likely to reside in low cholesterol regions. This will render $\gamma 1$-containing $\mathrm{GABA}_{\mathrm{A}} \mathrm{Rs}$ more prone to free diffusion, keeping them away from the synapse. In addition to modulating channel mobility, the composition of lipids can impact functional properties of pentameric ligand-gated ion channels through the interaction with the TM4 domain (Barrantes, 2015). However, when we mutated the amino acid residues of $\gamma 1$ to match those of $\gamma 2$ in the TM4 domain, the IPSC decay rate was unaffected (Figures 1C,E). Therefore, the change in the IPSC kinetics cannot be explained by the difference in the composition of the lipids surrounding $\gamma 1$ and $\gamma 2$ subunit-containing $\mathrm{GABA}_{\mathrm{A}}$ Rs.

In neurons, the mechanisms underlying clustering and mobility of $\mathrm{GABA}_{\mathrm{A}} \mathrm{Rs}$ are complex and depend in part on synaptic activity (Bannai et al., 2009). Although GABA Rs may interact with extracellular synaptic proteins (e.g., neurexin Zhang et al., 2010), we restrict our discussion to cytoplasmic proteins, as the mutation that switches IPSC kinetics is located in the large intracellular domain. So far, the only protein known to alter $\mathrm{GABA}_{\mathrm{A}} \mathrm{R}$ kinetics is GABARAP (Chen et al., 2000; Luu et al., 2006), which binds to both $\gamma 1$ and $\gamma 2 \mathrm{~L}$ subunits close to the TM4 domain (Nymann-Andersen et al., 2002), and is thus incompatible with our predicted binding site (Figure 1A). At the synapse, the $\alpha 2$ subunit interacts with the gephyrin-collibystin complex through the large intracellular domain (Saiepour et al., 2010). The same region of $\gamma 1$ and $\gamma 2 \mathrm{~L}$ subunits is responsible for binding to GABARAP, although this region does not include L353 or T349 residues (Nymann-Andersen et al., 2002). Finally, radixin constrains $\alpha 5$-containing $\mathrm{GABA}_{\mathrm{A}} \mathrm{Rs}$ to extrasynaptic regions of the plasma membrane (Hausrat et al., 2015). Out of all these proteins only gephyrin is endogenously expressed in HEK293 cells. However, direct binding of $\gamma 1$ or $\gamma 2 \mathrm{~L}$ subunits to gephyrin has not been demonstrated. Nevertheless, we cannot reject the possibility that the difference in decay rates is due to a differential interaction between a synapse-specific factor. Indeed recent studies have demonstrated a plethora of proteins at inhibitory synapses, many of which have unknown function (Uezu et al., 2016).

\section{REFERENCES}

Alldred, M. J., Mulder-Rosi, J., Lingenfelter, S. E., Chen, G., and Lüscher, B. (2005). Distinct $\gamma 2$ subunit domains mediate clustering and synaptic function of postsynaptic $\mathrm{GABA}_{\mathrm{A}}$ receptors and gephyrin. J. Neurosci. 25, 594-603. doi: 10.1523/JNEUROSCI.4011-04.2005

\section{CONCLUSION}

In conclusion, we have shown that $\gamma 1$ subunit incorporation in $\mathrm{GABA}_{\mathrm{A}}$ Rs slows the decay rate of IPSCs in artificial synapses and that the Leu353 residue is responsible. Our experiments in both HEK293 cells and neurons identified two novel observations. First, $\gamma 1$-containing receptors are localized at neuronal synapses, and thus may contribute to fast synaptic inhibition in the brain. At synapses, they exhibit similar confinement and mobilities to $\gamma 2 \mathrm{~L}$-containing $\mathrm{GABA}_{\mathrm{A}}$ Rs. Second, $\gamma 1$-containing $\mathrm{GABA}_{\mathrm{A}} \mathrm{Rs}$ have larger population of rapidly diffusing extrasynaptic receptors compared to $\gamma 2 \mathrm{~L}$-containing $\mathrm{GABA}_{\mathrm{A}}$ Rs. High mobility of extrasynaptic $\gamma 1$-containing $\mathrm{GABA}_{\mathrm{A}}$ Rs facilitates rapid tuning of receptor numbers at the synapse which may be required for homeostatic regulation of network activity in regions of the brain where $\gamma 1$ subunits are highly expressed (Pirker et al., 2000; Bannai et al., 2009; Esmaeili et al., 2009). As the key residue for altered synaptic kinetics (Leu353) has no effect on synaptic clustering propensities or diffusional properties of receptors, we conclude that this residue is important for synapse-specific alterations in gating properties that differ between $\gamma 1-$ and $\gamma 2 \mathrm{~L}$ containing $\mathrm{GABA}_{\mathrm{A}}$ Rs.

\section{AUTHOR CONTRIBUTIONS}

CLD performed the cloning of plasmids, the site-directed mutagenesis and the electrophysiology. AK also performed electrophysiology. ND performed all microscopy measurements. CLD, AK and ND analyzed the data; CLD, ND, JWL and PS conceived the study and all authors contributed to writing the manuscript.

\section{ACKNOWLEDGMENTS}

We thank Frederic Meunier (Queensland Brain Institute, University of Queensland) for mEos2 plasmid; QBI Advanced Imaging Facility for support in microscopy (funded through Australian Research Council (ARC) LIEF grant LE130100078). ND is supported by a University of Queensland Postdoctoral Research Fellowship. Project funding support was provided by the National Health and Medical Research Council (NHMRC; 1058542, 1060707, 1062183) and the ARC (LP120100297).

\section{SUPPLEMENTARY MATERIAL}

The Supplementary Material for this article can be found online at: http://journal.frontiersin.org/article/10.3389/fnmol.2017.001 78/full\#supplementary-material

Baer, K., Essrich, C., Balsiger, S., Wick, M. J., Harris, R. A., Fritschy, J. M., et al (2000). Rescue of $\gamma 2$ subunit-deficient mice by transgenic overexpression of the $\mathrm{GABA}_{\mathrm{A}}$ receptor $\gamma 2 \mathrm{~S}$ or $\gamma 2 \mathrm{~L}$ subunit isoforms. Eur. J. Neurosci. 12, 2639-2643. doi: 10.1046/j.1460-9568.2000.00159.x

Bannai, H., Levi, S., Schweizer, C., Inoue, T., Launey, T., Racine, V., et al. (2009). Activity-dependent tuning of inhibitory neurotransmission based on 
GABA $_{A}$ R diffusion dynamics. Neuron 62, 670-682. doi: 10.1016/j.neuron. 2009.04.023

Barrantes, F. J. (2015). Phylogenetic conservation of protein-lipid motifs in pentameric ligand-gated ion channels. Biochim. Biophys. Acta 1848, 1796-1805. doi: 10.1016/j.bbamem.2015.03.028

Chen, L., Wang, H., Vicini, S., and Olsen, R. W. (2000). The $\gamma$-aminobutyric acid type $A\left(G_{A B A}\right)$ receptor-associated protein (GABARAP) promotes $G_{A B A}$ receptor clustering and modulates the channel kinetics. Proc. Natl. Acad. Sci. U S A 97, 11557-11562. doi: 10.1073/pnas.190133497

Choquet, D., and Triller, A. (2013). The dynamic synapse. Neuron 80, 691-703. doi: 10.1016/j.neuron.2013.10.013

Clements, J. D. (1996). Transmitter timecourse in the synaptic cleft: its role in central synaptic function. Trends Neurosci. 19, 163-171. doi: 10.1016/s01662236(96)10024-2

Delaney, A. J., and Sah, P. (2001). Pathway-specific targeting of $\mathrm{GABA}_{\mathrm{A}}$ receptor subtypes to somatic and dendritic synapses in the central amygdala. J. Neurophysiol. 86, 717-723. Available online at: http://jn.physiology.org/content/86/2/717.long

Dixon, C., Sah, P., Lynch, J. W., and Keramidas, A. (2014). GABA A receptor $\alpha$ and $\gamma$ subunits shape synaptic currents via different mechanisms. J. Biol. Chem. 289, 5399-5411. doi: 10.1074/jbc.M113.514695

Dixon, C. L., Zhang, Y., and Lynch, J. W. (2015). Generation of functional inhibitory synapses incorporating defined combinations of $\mathrm{GABA}_{\mathrm{A}}$ or glycine receptor subunits. Front. Mol. Neurosci. 8:80. doi: 10.3389/fnmol.2015.00080

Ernst, D., and Köhler, J. (2013). Measuring a diffusion coefficient by single-particle tracking: statistical analysis of experimental mean squared displacement curves. Phys. Chem. Chem. Phys. 15, 845-849. doi: 10.1039/c2cp43433d

Esmaeili, A., Lynch, J. W., and Sah, P. (2009). GABA A receptors containing $\gamma 1$ subunits contribute to inhibitory transmission in the central amygdala. J. Neurophysiol. 101, 341-349. doi: 10.1152/jn.90991.2008

Gerrow, K., and Triller, A. (2010). Synaptic stability and plasticity in a floating world. Curr. Opin. Neurobiol. 20, 631-639. doi: 10.1016/j.conb.2010.06.010

Giannone, G., Hosy, E., Levet, F., Constals, A., Schulze, K., Sobolevsky, A. I., et al. (2010). Dynamic superresolution imaging of endogenous proteins on living cells at ultra-high density. Biophys. J. 99, 1303-1310. doi: 10.1016/j.bpj. 2010.06.005

Gonzalez-Burgos, G., Rotaru, D. C., Zaitsev, A. V., Povysheva, N. V., and Lewis, D. A. (2009). GABA transporter GAT1 prevents spillover at proximal and distal GABA synapses onto primate prefrontal cortex neurons. J. Neurophysiol. 101, 533-547. doi: 10.1152/jn.91161.2008

Hausrat, T. J., Muhia, M., Gerrow, K., Thomas, P., Hirdes, W., Tsukita, S., et al. (2015). Radixin regulates synaptic $\mathrm{GABA}_{\mathrm{A}}$ receptor density and is essential for reversal learning and short-term memory. Nat. Commun. 6:6872. doi: 10.1038/ncomms7872

Houston, C. M., and Smart, T. G. (2006). CaMK-II modulation of GABAA receptors expressed in HEK293, NG108-15 and rat cerebellar granule neurons. Eur. J. Neurosci. 24, 2504-2514. doi: 10.1111/j.1460-9568.2006.05145.x

Jacob, T. C., Bogdanov, Y. D., Magnus, C., Saliba, R. S., Kittler, J. T., Haydon, P. G., et al. (2005). Gephyrin regulates the cell surface dynamics of synaptic GABA A $_{\text {A }}$ receptors. J. Neurosci. 25, 10469-10478. doi: 10.1523/JNEUROSCI. 2267-05.2005

Jaqaman, K., Loerke, D., Mettlen, M., Kuwata, H., Grinstein, S., Schmid, S. L., et al. (2008). Robust single-particle tracking in live-cell time-lapse sequences. Nat. Methods 5, 695-702. doi: 10.1038/nmeth.1237

Kasugai, Y., Swinny, J. D., Roberts, J. D., Dalezios, Y., Fukazawa, Y., Sieghart, W., et al. (2010). Quantitative localisation of synaptic and extrasynaptic $\mathrm{GABA}_{\mathrm{A}}$ receptor subunits on hippocampal pyramidal cells by freeze-fracture replica immunolabelling. Eur. J. Neurosci. 32, 1868-1888. doi: 10.1111/j.1460-9568. 2010.07473.x

Lévi, S., Le Roux, N., Eugène, E., and Poncer, J. C. (2015). Benzodiazepine ligands rapidly influence $\mathrm{GABA}_{\mathrm{A}}$ receptor diffusion and clustering at hippocampal inhibitory synapses. Neuropharmacology 88, 199-208. doi: 10.1016/j. neuropharm.2014.06.002

Longsworth, L. G. (1953). Diffusion measurements, at $25^{\circ}$, of aqueous solutions of amino acids, peptides and sugars. J. Am. Chem. Soc. 75, 5705-5709. doi: $10.1021 / \mathrm{ja} 01118 \mathrm{a} 065$

Lozovaya, N. A., Kopanitsa, M. V., Boychuk, Y. A., and Krishtal, O. A. (1999). Enhancement of glutamate release uncovers spillover-mediated transmission by N-methyl-D-aspartate receptors in the rat hippocampus. Neuroscience 91 , 1321-1330. doi: 10.1016/s0306-4522(98)00638-1

Luu, T., Gage, P. W., and Tierney, M. L. (2006). GABA increases both the conductance and mean open time of recombinant $\mathrm{GABA}_{\mathrm{A}}$ channels co-expressed with GABARAP. J. Biol. Chem. 281, 35699-35708. doi: 10.1074/jbc.M605590200

Manley, S., Gillette, J. M., and Lippincott-Schwartz, J. (2010). Singleparticle tracking photoactivated localization microscopy for mapping singlemolecule dynamics. Methods Enzymol. 475, 109-120. doi: 10.1016/S00766879(10)75005-9

McDonald, B. J., and Moss, S. J. (1994). Differential phosphorylation of intracellular domains of $\gamma$-aminobutyric acid type A receptor subunits by calcium/calmodulin type 2-dependent protein kinase and cGMP-dependent protein kinase. J. Biol. Chem. 269, 18111-18117.

McKernan, R. M., and Whiting, P. J. (1996). Which GABA $A_{A}$-receptor subtypes really occur in the brain? Trends Neurosci. 19, 139-143. doi: 10.1016/s01662236(96)80023-3

Meier, J., and Grantyn, R. (2004). Preferential accumulation of $\mathrm{GABA}_{\mathrm{A}}$ receptor $\gamma$ $2 \mathrm{~L}$, not $\gamma 2 \mathrm{~S}$, cytoplasmic loops at rat spinal cord inhibitory synapses. J. Physiol. 559, 355-365. doi: 10.1113/jphysiol.2004.066233

Montes, J., Peña, J. M., DeFelipe, J., Herreras, O., and Merchan-Perez, A. (2015). The influence of synaptic size on AMPA receptor activation: a Monte Carlo model. PLoS One 10:e0130924. doi: 10.1371/journal.pone.0130924

Moss, S. J., Doherty, C. A., and Huganir, R. L. (1992). Identification of the cAMP-dependent protein kinase and protein kinase $\mathrm{C}$ phosphorylation sites within the major intracellular domains of the $\beta 1, \gamma 2 \mathrm{~S}$, and $\gamma 2 \mathrm{~L}$ subunits of the $\gamma$-aminobutyric acid type A receptor. J. Biol. Chem. 267, 14470-14476.

Muir, J., Arancibia-Carcamo, I. L., MacAskill, A. F., Smith, K. R., Griffin, L. D., and Kittler, J. T. (2010). NMDA receptors regulate $\mathrm{GABA}_{\mathrm{A}}$ receptor lateral mobility and clustering at inhibitory synapses through serine 327 on the $\gamma 2$ subunit. Proc. Natl. Acad. Sci. U S A 107, 16679-16684. doi: 10.1073/pnas.1000589107

Muir, J., and Kittler, J. T. (2014). Plasticity of $\mathrm{GABA}_{\mathrm{A}}$ receptor diffusion dynamics at the axon initial segment. Front. Cell. Neurosci. 8:151. doi: 10.3389/fncel. 2014.00151

Nakamura, Y., Darnieder, L. M., Deeb, T. Z., and Moss, S. J. (2015). Regulation of $\mathrm{GABA}_{\mathrm{A}}$ Rs by phosphorylation. Adv. Pharmacol. 72, 97-146. doi: 10.1016/bs apha.2014.11.008

Nielsen, T. A., DiGregorio, D. A., and Silver, R. A. (2004). Modulation of glutamate mobility reveals the mechanism underlying slow-rising AMPAR EPSCs and the diffusion coefficient in the synaptic cleft. Neuron 42, 757-771. doi: 10.1016/j. neuron.2004.04.003

Nusser, Z., Cull-Candy, S., and Farrant, M. (1997). Differences in synaptic GABA receptor number underlie variation in GABA mini amplitude. Neuron 19 697-709. doi: 10.1016/s0896-6273(00)80382-7

Nymann-Andersen, J., Wang, H., Chen, L., Kittler, J. T., Moss, S. J., and Olsen, R. W. (2002). Subunit specificity and interaction domain between $\mathrm{GABA}_{\mathrm{A}}$ receptor-associated protein (GABARAP) and $\mathrm{GABA}_{\mathrm{A}}$ receptors. J. Neurochem. 80, 815-823. doi: 10.1046/j.0022-3042.2002.00762.x

Oláh, S., Füle, M., Komlósi, G., Varga, C., Báldi, R., Barzó, P., et al. (2009). Regulation of cortical microcircuits by unitary GABA-mediated volume transmission. Nature 461, 1278-1281. doi: 10.1038/nature08503

Petrini, E. M., Nieus, T., Ravasenga, T., Succol, F., Guazzi, S., Benfenati, F., et al. (2011). Influence of $\mathrm{GABA}_{\mathrm{A}} \mathrm{R}$ monoliganded states on GABAergic responses. J. Neurosci. 31, 1752-1761. doi: 10.1523/JNEUROSCI.1453-10.2011

Pirker, S., Schwarzer, C., Wieselthaler, A., Sieghart, W., and Sperk, G. (2000). $\mathrm{GABA}_{\mathrm{A}}$ receptors: immunocytochemical distribution of 13 subunits in the adult rat brain. Neuroscience 101, 815-850. doi: 10.1016/s0306-4522(00) 00442-5

Postlethwaite, M., Hennig, M. H., Steinert, J. R., Graham, B. P., and Forsythe, I. D. (2007). Acceleration of AMPA receptor kinetics underlies temperaturedependent changes in synaptic strength at the rat calyx of Held. J. Physiol. 579, 69-84. doi: 10.1113/jphysiol.2006.123612

Qian, H., Sheetz, M. P., and Elson, E. L. (1991). Single particle tracking. Analysis of diffusion and flow in two-dimensional systems. Biophys. J. 60, 910-921. doi: 10.1016/s0006-3495(91)82125-7

Renner, M., Choquet, D., and Triller, A. (2009). Control of the postsynaptic membrane viscosity. J. Neurosci. 29, 2926-2937. doi: 10.1523/JNEUROSCI. 4445-08.2009 
Rusakov, D. A., Savtchenko, L. P., Zheng, K., and Henley, J. M. (2011). Shaping the synaptic signal: molecular mobility inside and outside the cleft. Trends Neurosci. 34, 359-369. doi: 10.1016/j.tins.2011.03.002

Saiepour, L., Fuchs, C., Patrizi, A., Sassoè-Pognetto, M., Harvey, R. J., and Harvey, K. (2010). Complex role of collybistin and gephyrin in $\mathrm{GABA}_{\mathrm{A}}$ receptor clustering. J. Biol. Chem. 285, 29623-29631. doi: 10.1074/jbc.M110. 121368

Salvatico, C., Specht, C. G., and Triller, A. (2015). Synaptic receptor dynamics: from theoretical concepts to deep quantification and chemistry in cellulo. Neuropharmacology 88, 2-9. doi: 10.1016/j.neuropharm.2014.09.020

Schikorski, T., and Stevens, C. F. (1997). Quantitative ultrastructural analysis of hippocampal excitatory synapses. J. Neurosci. 17, 5858-5867.

Tretter, V., Jacob, T. C., Mukherjee, J., Fritschy, J. M., Pangalos, M. N., and Moss, S. J. (2008). The clustering of $\mathrm{GABA}_{\mathrm{A}}$ receptor subtypes at inhibitory synapses is facilitated via the direct binding of receptor $\alpha 2$ subunits to gephyrin. J. Neurosci. 28, 1356-1365. doi: 10.1523/JNEUROSCI.5050-07.2008

Uezu, A., Kanak, D. J., Bradshaw, T. W., Soderblom, E. J., Catavero, C. M., Burette, A. C., et al. (2016). Identification of an elaborate complex mediating postsynaptic inhibition. Science 353, 1123-1129. doi: 10.1126/ science.aag0821

Wahl, L. M., Pouzat, C., and Stratford, K. J. (1996). Monte Carlo simulation of fast excitatory synaptic transmission at a hippocampal synapse. J. Neurophysiol. 75, 597-608.

Wu, X., Wu, Z., Ning, G., Guo, Y., Ali, R., Macdonald, R. L., et al. (2012). $\gamma$ Aminobutyric acid type $\mathrm{A}\left(\mathrm{GABA}_{\mathrm{A}}\right)$ receptor $\alpha$ subunits play a direct role in synaptic versus extrasynaptic targeting. J. Biol. Chem. 287, 27417-27430. doi: 10.1074/jbc.M112.360461

Zagranichnaya, T. K., Wu, X., Danos, A. M., and Villereal, M. L. (2005). Gene expression profiles in HEK-293 cells with low or high store-operated calcium entry: can regulatory as well as regulated genes be identified? Physiol. Genomics 21, 14-33. doi: 10.1152/physiolgenomics.00099.2004

Zhang, C., Atasoy, D., Arac, D., Yang, X., Fucillo, M. V., Robison, A. J., et al. (2010). Neurexins physically and functionally interact with $\mathrm{GABA}_{\mathrm{A}}$ receptors. Neuron 66, 403-416. doi: 10.1016/j.neuron.2010.04.008

Zuber, B., Nikonenko, I., Klauser, P., Muller, D., and Dubochet, J. (2005). The mammalian central nervous synaptic cleft contains a high density of periodically organized complexes. Proc. Natl. Acad. Sci. U S A 102, 19192-19197. doi: 10.1073/pnas.0509527102

Conflict of Interest Statement: The authors declare that the research was conducted in the absence of any commercial or financial relationships that could be construed as a potential conflict of interest.

Copyright (C) 2017 Dixon, Sah, Keramidas, Lynch and Durisic. This is an open-access article distributed under the terms of the Creative Commons Attribution License (CC BY). The use, distribution or reproduction in other forums is permitted, provided the original author(s) or licensor are credited and that the original publication in this journal is cited, in accordance with accepted academic practice. No use, distribution or reproduction is permitted which does not comply with these terms. 